\title{
Large Ground-State Entropy Changes for Hydrogen Atom Transfer Reactions of Iron Complexes
}

\author{
Elizabeth A. Mader, Ernest R. Davidson, and James M. Mayer \\ University of Washington, Campus Box 351700, Seattle, WA, 98195-1700, USA, E-mail: \\ mayer@chem.washington.edu
}

\section{Abstract}

Reported herein are the hydrogen atom transfer (HAT) reactions of two closely related dicationic iron tris $\alpha$-diimine complexes. $\mathbf{F e}^{\mathbf{I I}}\left(\mathbf{H}_{2} \mathbf{b i p}\right)$ (iron(II) tris[2,2'-bi-1,4,5,6-tetra-hydropyrimidine] diperchlorate) and $\mathbf{F e}^{\mathbf{I I}}\left(\mathbf{H}_{2} \mathbf{b i m}\right.$ ) (iron(II) tris[2,2'-bi-2-imidazoline]diperchlorate) both transfer $\mathbf{H}^{*}$ to TEMPO (2,2,6,6-tetramethyl-1-piperidinoxyl) to yield the hydroxylamine, TEMPO-H, and the

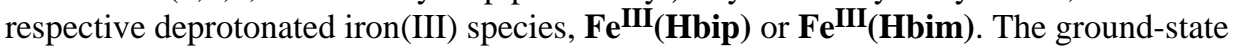
thermodynamic parameters in $\mathrm{MeCN}$ were determined for both systems using both static and kinetic measurements. For $\mathbf{F e}^{\mathbf{I I}}\left(\mathbf{H}_{2}\right.$ bip $)+$ TEMPO: $\Delta G^{\circ}=-0.3 \pm 0.2 \mathrm{kcal} \mathrm{mol}^{-1}, \Delta H^{\circ}=-9.4 \pm 0.6 \mathrm{kcal}$ $\mathrm{mol}^{-1}, \Delta S^{\circ}=-30 \pm 2 \mathrm{cal} \mathrm{mol}^{-1} \mathrm{~K}^{-1}$. For $\mathbf{F e}^{\mathbf{I I}}\left(\mathbf{H}_{2} \mathbf{b i m}\right)+$ TEMPO: $\Delta G^{\circ}=5.0 \pm 0.2 \mathrm{kcal} \mathrm{mol}^{-1}, \Delta H$ ${ }^{\circ}=-4.1 \pm 0.9 \mathrm{kcal} \mathrm{mol}^{-1}, \Delta S^{\circ}=-30 \pm 3 \mathrm{cal} \mathrm{mol}^{-1} \mathrm{~K}^{-1}$. The large entropy changes for these reactions, $\left|\mathrm{T} \Delta S^{\circ}\right|=9 \mathrm{kcal} \mathrm{mol}^{-1}$ at $298 \mathrm{~K}$, are exceptions to the traditional assumption that $\Delta S^{\circ} \approx 0$ for simple HAT reactions. Various studies indicate that hydrogen-bonding, solvent effects, ion-pairing, and iron spin-equilibria do not make major contributions to the observed $\Delta S^{\circ}{ }_{\text {HAT }}$. Instead, this effect arises primarily from changes in vibrational entropy upon oxidation of the iron center. Measurement of the electron transfer half-reaction entropy, $\left|\Delta S^{\circ} \mathrm{Fe}(\mathrm{H} 2 \mathrm{bim}) / \mathrm{ET}\right|=29 \pm 3 \mathrm{cal} \mathrm{mol}^{-1} \mathrm{~K}^{-1}$, is consistent with a vibrational origin. This conclusion is supported by UHF/6-31G* calculations on the simplified reaction $\left[\mathrm{Fe} \mathrm{II}_{(\mathrm{H}} \mathrm{N}=\mathrm{CHCH}=\mathrm{NH}_{2}\right)_{2}\left(\mathrm{H}_{2}\right.$ bim $\left.)\right]^{2+} \cdot \cdots \mathrm{ONH}_{2} \leftrightarrows$

$\left[\mathrm{Fe}^{\mathrm{II}}\left(\mathrm{H}_{2} \mathrm{~N}=\mathrm{CHCH}=\mathrm{NH}_{2}\right)_{2}(\mathrm{Hbim})\right]^{2+} \cdot \bullet^{+} \mathrm{HONH}_{2}$. The discovery that $\Delta S^{\circ}{ }_{\mathrm{HAT}}$ can deviate significantly from zero has important implications on the study of HAT and proton-coupled electron transfer (PCET) reactions. For instance, these results indicate that free energies, rather than enthalpies, should be used to estimate the driving force for HAT when transition metal centers are involved.

\section{Introduction}

Hydrogen atom transfer (HAT) is one of the most common and fundamental chemical reactions (eq 1). It is a cornerstone of organic free-radical chemistry, from combustion to the

$$
\mathrm{A}-\mathrm{H}+\mathrm{B}^{\bullet} \rightarrow \mathrm{A}^{\bullet}+\mathrm{H}-\mathrm{B}
$$

action of antioxidants both in vitro and in vivo. ${ }^{1} \mathrm{HAT}$ can be defined as the concerted movement of a proton and an electron $\left(e^{-}+\mathrm{H}^{+} \equiv \mathrm{H}^{*}\right)$ in a single kinetic step where both the proton and the electron originate from the same reactant and travel to the same product. HAT is one type of the broad class of proton-coupled electron transfer (PCET) reactions, which also includes reactions where the proton and electron are separated. ${ }^{2-6}$ In recent years it has become clear that HAT involving transition metal species is very common, occurring in discrete metal complexes, metalloprotein active sites, and most likely sites on metal oxide surfaces. ${ }^{2-4,7,8}$ 
Among the many metalloenzymes that utilize HAT reactions are lipoxygenases, ${ }^{9}$ ribonucleotide reductases, $3 \mathrm{~b}, 7 \mathrm{a}$ and methane monooxygenases. ${ }^{10}$

For more than 70 years, numerous HAT reactions have been measured and understood using the Bell-Evans-Polanyi equation (eq 2). This equation correlates the activation energy, $E_{\mathrm{a}}$, with the enthalpic driving force of the reaction $(\Delta H)$, using two parameters $(\alpha, \beta)$ that are specific to a set of reactions rather than to all HAT. ${ }^{11,12}$ Using this thermochemical perspective (rather than one based on electronic structure), we have found strong analogies between organic and metal-mediated HAT reactions. ${ }^{13,14}$ Under standard conditions, the $\Delta H$ for an HAT reaction is simply the difference between the bond dissociation enthalpies (BDEs) of AH and $\mathrm{BH}$ (eq 3 ). The correlation indicated by eqs (2) and (3) is one of the primary historical reasons why chemists are so focused on BDEs (for instance, why tables of BDEs appear in many organic chemistry texts).

$$
\begin{gathered}
E_{\mathrm{a}}=\alpha(\Delta H)+\beta \\
\Delta H^{\circ}=\mathrm{BDE}(\mathrm{AH})-\mathrm{BDE}(\mathrm{BH})
\end{gathered}
$$

Like the Polanyi equation, Marcus Theory correlates activation barriers with driving force, but the Marcus approach uses free energies rather than enthalpies. ${ }^{17}$ It was developed for electron transfer (ET) reactions but has been applied to transfers of protons, hydrides, and other groups. 15 Recently, we have shown that a wide range of HAT rate constants can be understood and predicted using Marcus Theory, specifically the Marcus cross relation (eq 4). ${ }^{14,16}$ The rate constant of $\mathrm{HAT}$ from $\mathrm{AH}$ to $\mathrm{B}^{\bullet}\left(\mathrm{eq} 1, k_{\mathrm{AB}}\right)$ is related to the equilibrium constant, $K_{\mathrm{AB}}$, as well as the rate constants of the component degenerate HAT 'self-exchange' reactions $\left(\mathrm{AH}+\mathrm{A}^{\circ}\right.$ $\left.\rightarrow \mathrm{A}^{\bullet}+\mathrm{HA} ; k_{\mathrm{AA}}\right)$. The frequency factor, $f$, is usually close to unity. ${ }^{17}$ This treatment has been successfully applied to

$$
k_{A B}=\sqrt{k_{A A} k_{B B} K_{A B} f}
$$

reactions of $\mathrm{C}-\mathrm{H}, \mathrm{N}-\mathrm{H}$, and $\mathrm{O}-\mathrm{H}$ bonds including both metal and organic compounds, although there are exceptions. ${ }^{14}$

The difference between the Polanyi correlation with $\Delta H^{\circ}$ and the Marcus treatment with $\Delta G^{\circ}$ has not been of serious concern because HAT reactions are typically assumed to have groundstate entropies of reaction close to zero. ${ }^{18}$ When $\Delta S^{\circ} \approx 0, \Delta G^{\circ} \approx \Delta H^{\circ}=\Delta$ BDE. Assuming= $\Delta S^{\circ} \approx 0$ seems reasonable because these reactions do not involve a change in the number of molecules or their charge or overall size. For analogous reasons, $\mathrm{AH}$ and $\mathrm{A}^{\bullet}$ are often assumed to have similar entropies, so that $\Delta S^{\circ}$ for bond homolysis $\left(\mathrm{A}-\mathrm{H} \rightarrow \mathrm{A}^{\bullet}+\mathrm{H}^{\circ}\right)$ is very close to $S$ ${ }^{\circ}\left(\mathrm{H}^{*}\right)$. This is also a key assumption in the increasingly common determination of BDEs from solution $\mathrm{p} K_{\mathrm{a}}$ and $E_{1 / 2}$ values, as discussed in more detail below. ${ }^{19-24}$

Described here are detailed studies of HAT reactions involving iron complexes (eqs 5, 6 below) that have large entropies of reaction, $\left|\Delta S^{\circ}\right| \approx 30 \mathrm{cal} \mathrm{K}^{-1} \mathrm{~mol}^{-1}$. A preliminary report on eq 5 emphasized its negative activation enthalpy $\left(\Delta H^{+}\right)$and its quantitative prediction by the Marcus cross relation (eq 4). ${ }^{16}$ The large entropy change in reaction 5 and 6 is equivalent to a change in equilibrium constant of $4 \times 10^{6}\left(\Delta \ln K_{\mathrm{eq}}=\Delta S^{\circ} / \mathrm{R}\right)$ and contributes $\left|\mathrm{T} \Delta S^{\circ}\right|=9 \mathrm{kcal} \mathrm{mol}^{-1}$ to the free energy of reaction at $298 \mathrm{~K}$. In this system, BDEs calculated from $\mathrm{p} K_{\mathrm{a}}$ and $E_{1 / 2}$ values with the assumption that $S^{\circ}\left(\mathrm{A}^{\circ}\right) \approx S^{\circ}(\mathrm{AH})$ are in error by $9 \mathrm{kcal} \mathrm{mol}^{-1}$. The success of the Marcus treatment demonstrates that these reactions should be analyzed using free energies rather than enthalpies as in the traditional Polanyi equation (eq 2). Herein, we explore the origin of this large entropy using both experiment and theory, and discuss the implications of the large $\left|\Delta S^{\circ}\right|$ 


\section{Results}

The HAT reactions of two closely related iron(II) tris $(\alpha$-diimine) complexes have been studied, $\left[\mathrm{Fe}^{\mathrm{II}}\left(\mathrm{H}_{2} \text { bip }\right)_{3}\right]^{2+}\left(\mathbf{F e}^{\mathbf{I I}}\left(\mathbf{H}_{2}\right.\right.$ bip $), \mathrm{H}_{2}$ bip = 2,2'-bi-1,4,5,6-tetrahydropyrimidine $)$ and $\left[\mathrm{Fe}^{\mathrm{II}}\left(\mathrm{H}_{2} \text { bim }\right)_{3}\right]^{2+},\left(\mathbf{F e}^{\mathbf{I I}}\left(\mathbf{H}_{2}\right.\right.$ bim $), \mathrm{H}_{2}$ bim $=2,2^{\prime}$-bi-2-imidazoline $)$. Fe $\mathbf{e}^{\mathbf{I I}}\left(\mathbf{H}_{2} \mathbf{b i p}\right)$ and $\mathbf{F e}^{\mathrm{II}}\left(\mathbf{H}_{2} \mathbf{b i m}\right)$ react rapidly at room temperature with the stable nitroxyl TEMPO in anaerobic acetonitrile to give the hydroxylamine TEMPO-H and the deprotonated iron(III) complex, $\left[\mathrm{Fe}^{\mathrm{III}}\left(\mathrm{H}_{2} \text { bip }\right)(\mathrm{Hbip})\right]^{2+}\left(\mathbf{F e}^{\mathrm{III}}(\mathbf{H b i p})\right)$ or $\left[\mathrm{Fe}^{\mathrm{III}}\left(\mathrm{H}_{2} \text { bim }\right)(\mathrm{Hbim})\right]^{2+}\left(\mathbf{F e}^{\mathrm{III}}(\mathbf{H b i m})\right)($ eqs 5,6$){ }^{14}$, 16 The reaction is net HAT to the organic radical by the concerted transfer of one proton (from the ligand) and one electron (from oxidation of the iron). In these equations the two ancillary ligands denoted by N-N are the same as the ligand, L, drawn in full for the respective $\mathrm{Fe}$ (II) complexes $\left(\mathrm{H}_{2}\right.$ bip or $\mathrm{H}_{2}$ bim $)$. The iron complexes are of the general form $\mathbf{F e}^{n}\left(\mathbf{H}_{x} \mathbf{L}\right)$ where $n$ is the oxidation state of the iron and $x$ indicates the protonation state of the ligand.
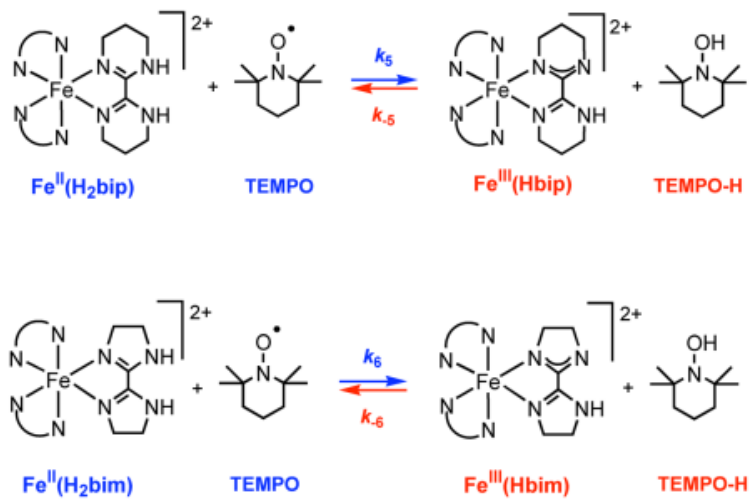

\section{Characterization}

The four iron species in eqs 5 and 6 have been previously reported, 25,26 including crystal structures for $\mathbf{F e}^{\mathbf{I I}_{(}}\left(\mathbf{H}_{2} \mathbf{b i m}\right), \mathbf{F e}^{\mathbf{I I I}}(\mathbf{H b i m})$, and the fully protonated $\left[\mathrm{Fe}^{\mathrm{III}}\left(\mathrm{H}_{2} \text { bim }\right)_{3}\right]\left[\mathrm{ClO}_{4}\right]_{3}$ $\left(\mathrm{Fe}^{\mathrm{III}}\left(\mathrm{H}_{2}\right.\right.$ bim $\left.)\right) .{ }^{27}$ While structures of $\mathbf{F e}^{\mathbf{I I}}\left(\mathbf{H}_{2}\right.$ bip $)$ or $\mathbf{F e}^{\mathrm{III}}(\mathbf{H b i p})$ are not available, X-ray quality crystals of the fully protonated iron(III) species, $\left[\mathrm{Fe}^{\mathrm{III}}\left(\mathrm{H}_{2} \mathrm{bip}\right)_{3}\right]\left[\left(\mathrm{ClO}_{4}\right)_{3}\right]$

$\left(\mathbf{F e}^{\mathrm{III}}\left(\mathrm{H}_{2} \mathbf{b i p}\right)\right.$ ) have been obtained from $\mathrm{MeCN}_{2} \mathrm{Et}_{2} \mathrm{O}$ (Tables 1, S5; Figure 1A). The structure contains a standard pseudo- $D_{3 \mathrm{~d}}$ tris(chelate) ion whose $\mathrm{NH}$ protons are hydrogen bonded to the perchlorate counter-ions, similar to all three of the $\mathbf{F e}^{\boldsymbol{n}}\left(\mathbf{H}_{\boldsymbol{x}} \mathbf{b i m}\right)$ complexes, Table 2 . The three $\mathrm{H}_{2}$ bip ligands in $\mathbf{F e}^{\mathbf{I I I}}\left(\mathbf{H}_{2}\right.$ bip) have similar diimine bite angles, $\mathrm{N}-\mathrm{Fe}-\mathrm{N}=81.3 \pm 0.2^{\circ}$, but their N-C-C-N torsion angles vary by $>10^{\circ}$. The distortion minimizes steric interactions between the chair conformations of the $\mathrm{H}_{2}$ bip ligands. This is in contrast to the three $\mathbf{F e}^{n}\left(\mathbf{H}_{x} \mathbf{b i m}\right)$ complexes which have essentially planar ligands (N-C-C-N torsion $<0.06^{\circ}$ ).

The Fe-N distances in $\mathbf{F e} \mathbf{e}^{\mathbf{I I I}}\left(\mathbf{H}_{2}\right.$ bip) range from 1.954(3) - 1.962(3) $\AA$. These are indicative of a low-spin iron(III) center, consistent with structures of related Fe(III) diimines. ${ }^{28,29}$ Solid state magnetic measurements ${ }^{26 a}$ have shown that $\mathbf{F e}^{\mathbf{I I I}}\left(\mathbf{H}_{2}\right.$ bip) is low spin at $100 \mathrm{~K}$ (the Xray data collection temperature), and undergoes a gradual spin-state transition from $200-400$ K. Fe ${ }^{\mathrm{III}}(\mathbf{H b i p})$ and $\mathbf{F e}^{\mathrm{II}}\left(\mathbf{H}_{2}\right.$ bip) behave similarly. ${ }^{26}$ In contrast, the three analogous $\mathbf{F e}^{n}\left(\mathbf{H}_{x} \mathbf{b i m}\right.$ ) complexes are exclusively high-spin above $120 \mathrm{~K}^{26}$ (the structure of $\mathbf{F e}^{\mathrm{III}}\left(\mathbf{H}_{2} \mathbf{b i m}\right)$ discussed here was obtained at $\left.161 \mathrm{~K}\right)$. This difference in spin state is consistent with the $\mathrm{Fe}-\mathrm{N}$ distances in $\mathbf{F e} \mathbf{e}^{\mathrm{III}}\left(\mathbf{H}_{2}\right.$ bip) being on average $0.12 \AA$ shorter than those in $\mathbf{F e}^{\mathrm{IIII}}\left(\mathrm{H}_{2} \mathbf{b i m}\right){ }^{28 \mathrm{~b}} \mathrm{In} \mathrm{Fe}(\mathrm{III})$ complexes, $d(\mathrm{Fe}-\mathrm{N})$ are typically $\sim 0.12 \AA$ shorter for low-spin vs. high-spin complexes; for Fe(II), the effect is slightly larger as $\Delta d(\mathrm{Fe}-\mathrm{N}) \sim 0.2 \AA .^{28 \mathrm{~b}}$ In addition, 
we observe a ca. $0.1 \AA ̊$ difference between bond distances to high-spin Fe(III) vs. high-spin Fe (II).

The literature preparation of TEMPO-H by dithionite reduction of TEMPO ${ }^{30}$ has been improved and an X-ray structure has been obtained using crystals prepared by sublimation (Tables 2 and S5; Figure 1B). The hydroxyl hydrogens were located from the difference map and refined. The asymmetric unit contains three TEMPO-H molecules and one water molecule that are hydrogen-bonded in a chain. The $d(\mathrm{~N}-\mathrm{O})$ in TEMPO-H $(1.46 \pm 0.06 \AA)$ is substantially longer than that in TEMPO $(1.283(9) \AA)^{31}$ because the radical has a partial $\mathrm{N}-\mathrm{O} \pi$ bond.

\section{Kinetics and Thermodynamics}

A. $\mathbf{F e}^{\mathrm{Il}}\left(\mathbf{H}_{2}\right.$ bip) + TEMPO-The reaction between $\mathbf{F e}^{\mathrm{II}}\left(\mathbf{H}_{2} \mathbf{b i p}\right)$ and TEMPO (eq 5) is close to isoergic in $\mathrm{MeCN}$ at $298 \mathrm{~K}\left(\Delta G^{\circ}=-0.3 \pm 0.2 \mathrm{kcal} \mathrm{mol}^{-1}\right)$, which allows both the forward $\left(k_{5}\right)$ andreverse $\left(k_{-5}\right)$ rate constants to be measured directly. Kinetics have been measured in both directions by stopped-flow rapid scanning UV-Visible spectrophotometry under pseudofirst order conditions. In the forward direction with excess TEMPO, the disappearance of $\mathbf{F e}^{\mathbf{I I}}\left(\mathbf{H}_{2}\right.$ bip $)\left(\lambda_{\max }=510 \mathrm{~nm}\right)$ and concomitant growth of $\mathbf{F e}^{\mathbf{I I I}}(\mathbf{H b i p})\left(\lambda_{\max }=636 \mathrm{~nm}\right)$ was observed (Figure 2A). The spectra were fit over the entire wavelength region observed (a 225 $\mathrm{nm}$ window) using the OLIS SVD global analysis software; ${ }^{32}$ the match at one wavelength is shown in Figure 2B. The data follow a first-order kinetic model for $>4$ half lives. The derived pseudo-first order rate constants vary linearly with [TEMPO] up to $0.16 \mathrm{M}$ (1600 equiv), and are independent of the initial concentration of $\mathbf{F e}^{\mathbf{I I}}\left(\mathbf{H}_{2} \mathbf{b i p}\right)$ from $0.10-0.28 \mathrm{mM}$, Figure S1. These data imply a simple second order kinetic rate law $\mathbb{R}=k_{5}\left[\mathbf{F e}^{\mathbf{I I}}\left(\mathbf{H}_{2} \mathbf{b i p}\right)\right][\mathrm{TEMPO}]$ with $k_{5}=260 \pm 30 \mathrm{M}^{-1} \mathrm{~s}^{-1}$ at $298 \mathrm{~K}$ (all rate and equilibrium constants and thermochemical values in this report are in $\mathrm{MeCN}$ unless otherwise indicated). For the reverse direction,

$\mathbf{F e}^{\text {III }}($ Hbip) + TEMPO-H, the pseudo-first order rate constants are linear with [TEMPO-H] up to $0.05 \mathrm{M}$ (but not above this concentration, see below). The derived second order rate constant $k_{-5}$ is $150 \pm 20 \mathrm{M}^{-1} \mathrm{~s}^{-1}$ (Figures S1, S2).

The rate constants $k_{5}$ and $k_{-5}$ were measured over the temperature range $277-328 \mathrm{~K}$. Remarkably, $k_{5}$ shows a small but definite decrease as the temperature increases. Eyring analysis gives $\Delta H_{5}{ }^{\ddagger}=-2.7 \pm 0.4 \mathrm{kcal} \mathrm{mol}^{-1} ; \Delta S_{5}^{\ddagger}=-57 \pm 8 \mathrm{cal} \mathrm{mol}^{-1} \mathrm{~K}^{-1}$ and $\Delta H_{-5}{ }^{\ddagger}=6.7$ $\pm 0.4 \mathrm{kcal} \mathrm{mol}^{-1} ; \Delta S_{-5}{ }^{\ddagger}=-26 \pm 2 \mathrm{cal} \mathrm{mol}^{-1} \mathrm{~K}^{-1}$. The ratio of $k_{5} / k_{-5}$ is the equilibrium constant $K_{5}$ (Figure 3, blue circles). At $298 \mathrm{~K}, K_{5}=1.7 \pm 0.3$, close to one, but it is highly temperature dependent. Van't Hoff analysis yields $\Delta H^{\circ}{ }_{5}=-9.4 \pm 0.6 \mathrm{kcal} \mathrm{mol}^{-1}$ and $\Delta S^{\circ}{ }_{5}=-30 \pm 2 \mathrm{cal}$ $\mathrm{mol}^{-1} \mathrm{~K}^{-1}$. These are unusually large ground-state entropy values for HAT reactions. All errors are reported as $\pm 2 \sigma$ based on fits weighted with the errors propagated from experimental measurements (see Experimental Section).

$K_{5}$ was independently measured using static UV-Vis experiments. Kinetically equilibrated mixtures of $\mathbf{F e}^{\mathbf{I I}}\left(\mathbf{H}_{2} \mathbf{b i p}\right)$ and TEMPO in MeCN were perturbed with aliquots of TEMPO and TEMPO-H (Figure S3). After each perturbation, the optical spectrum was deconvoluted into its component absorbances of $\mathbf{F e}^{\mathbf{I I I}}(\mathbf{H b i p}), \mathbf{F e}^{\mathbf{I I}}\left(\mathbf{H}_{2} \mathbf{b i p}\right)$, and TEMPO (TEMPO-H has no significant absorbance in this spectral region). The resulting equilibrium constants determined over a range of conditions were then averaged to give a single value (see Experimental Section and Table S1). Over a range of temperatures $(285-322 \mathrm{~K})$, these static measurements closely match the values obtained from the kinetic data: at $298 \mathrm{~K}, K_{5}$ (static) $=1.9 \pm 0.3 \mathrm{vs.} K_{5}$ (kinetic) $=1.7 \pm 0.3$. Figure 3 shows this close agreement between static (blue diamonds) and kinetic (blue circles) data. These two independent measures of the equilibrium constant give the same ground-state enthalpy and entropy changes within error, confirming the large ground state entropy associated with this reaction (Table 3). 
B. Fe"l $\left(\mathbf{H}_{\mathbf{2}} \mathbf{b i m}\right)+$ TEMPO-Stopped-flow kinetics for the thermodynamically downhill reaction of $\mathbf{F e}^{\mathrm{III}}(\mathbf{H b i m})+$ TEMPO-H, the reverse of reaction $6\left(k_{-6}\right)$, have been previously described ${ }^{33}$ including the temperature dependence and activation parameters (Table 3 ). The rate constant for the uphill reaction, $k_{6}$, has been determined by stopped-flow UV-Vis spectrophotometry using second-order approach to equilibrium conditions with a large excess of TEMPO (1000 - 7000 equiv). Global analyses of the spectra with SPECFITTM, 34 over the entire wavelength range collected and using the values of $k_{-6}$ measured above, gave the second order rate constants, $k_{6}$. The derived second order rate constants are independent of the concentration of TEMPO up to $0.46 \mathrm{M}$ (7000 equiv), as shown in the Supporting Information, together with typical spectral traces and a kinetic fit (Figures S4-S7). At $298 \mathrm{~K}, k_{6}=0.62 \pm$ $0.08 \mathrm{M}^{-1} \mathrm{~s}^{-1} ; k_{-6}=(3.1 \pm 0.1) \times 10^{3} \mathrm{M}^{-1} \mathrm{~s}^{-1}$. Eyring plots of rate constants from 288 to 338 $\mathrm{K}$ (Figure 4) give the activation parameters in Table 3 .

As in the $\mathbf{F e}^{\mathbf{I I}}\left(\mathbf{H}_{2} \mathbf{b i p}\right)$ case above, the equilibrium constant $K_{6}$ is given by $k_{6} / k_{-6}$ and is highly temperature dependent: $\Delta H_{6}^{\circ}=-4.1 \pm 0.9 \mathrm{kcal} \mathrm{mol}^{-1}, \Delta S^{\circ}{ }_{6}=-30 \pm 3 \mathrm{cal} \mathrm{mol}^{-1} \mathrm{~K}^{-1}$. These parameters were independently determined using static UV-Vis experiments $(278-317 \mathrm{~K})$ employing a method similar to that above but accounting for the fact that $K_{6}$ favors reactants much more strongly than $K_{5}$. The values agree with those from the kinetic measurements quite well: at $298 \mathrm{~K}, K_{6}$ (static) $=(3.0 \pm 0.5) \times 10^{-4}$ vs. $K_{6}$ (kinetic) $=(2.0 \pm 0.3) \times 10^{-4}$. The van't Hoff plots (shown in red at the bottom of Figure 3 ) show that the static and kinetic data yield the same ground-state enthalpy and entropy values within error, Table 4.

C. Further studies of the molecularity of the equilibria-The equilibrium constants $K_{5}$ and $K_{6}$ are ratios of opposing second-order rate constants, as described above, and are therefore unitless (eq 7, $\mathrm{H}_{2} \mathrm{~L}=\mathrm{H}_{2}$ bip $(i=5)$ or $\mathrm{H}_{2}$ bim $(i=6)$ ). The reactions of $\mathbf{F e}^{\mathbf{I I}}\left(\mathbf{H}_{2} \mathbf{L}\right)$ are first order in

$$
K_{i}=\frac{k_{i}}{k_{-i}} \frac{\left[\mathbf{F e}^{\mathrm{III}}(\mathbf{H L})\right][\text { TEMPO }-\mathbf{H}]}{\left[\mathbf{F e}^{\mathrm{II}}\left(\mathbf{H}_{\mathbf{2}} \mathbf{L}\right)\right][\text { TEMPO }]}
$$

[TEMPO] over all accessible concentrations. However, the reactions of $\mathbf{F e}^{\mathrm{III}}(\mathbf{H L})$ show saturation behavior at high [TEMPO-H], with $\mathbf{F e}^{\mathrm{III}}$ (Hbip) at [TEMPO-H] $>0.2 \mathrm{M}$ and with $\mathbf{F e}^{\mathrm{III}}($ Hbim) at [TEMPO-H] $>0.01 \mathrm{M}$. Such saturation behavior is common for reactions which have a rapid pre-equilibrium step, ${ }^{35}$ and suggests that a hydrogen bonded adduct dominates at high concentrations (e.g., eq 8). Fitting the $\mathbf{F e}^{\mathbf{I I I}}$ (Hbip) kinetics to the saturation rate law (eq 9 ,

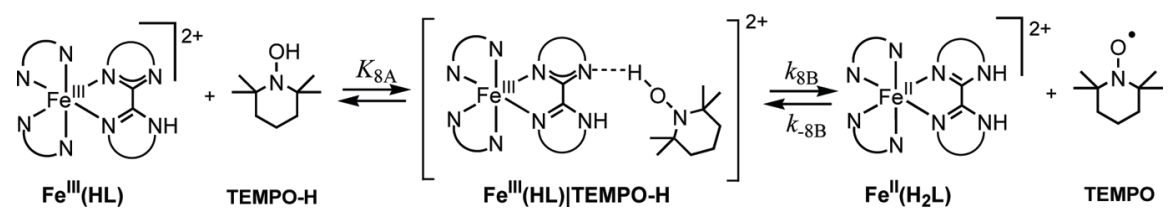

$$
k_{\text {obs }}=\frac{K_{8 A} k_{8 B}[\text { TEMPO }-\mathrm{H}]}{1+K_{8 A}[\text { TEMPO }-\mathrm{H}]}
$$

derived for conditions of high [TEMPO-H] where $k_{-8 \mathrm{~B}}$ is negligible) gives values for the preequilibrium of $K_{8 \mathrm{~A}}=3.1 \pm 0.3 \mathrm{M}^{-1}$ and $k_{8 \mathrm{~B}}=59 \pm 6 \mathrm{~s}^{-1}$. Consistent with this analysis, the product $K_{8 \mathrm{~A}} k_{8 \mathrm{~B}}\left(=183 \pm 20 \mathrm{M}^{-1} \mathrm{~s}^{-1}\right)$ is equal within error to the value of $k_{-5}$ measured at lower [TEMPO-H], $150 \pm 20 \mathrm{M}^{-1} \mathrm{~s}^{-1}$. For $\mathbf{F e}^{\mathrm{III}}(\mathbf{H b i m})+\mathrm{TEMPO}-\mathrm{H}$, the pre-equilibrium values are $K_{8 \mathrm{~A}}=56.6 \pm 1.7 \mathrm{M}^{-1}$ and $k_{8 \mathrm{~B}}=57.4 \pm 1.8 \mathrm{~s}^{-1}$ (Figure $\mathrm{S} 8 ; K_{8 \mathrm{~A}} k_{8 \mathrm{~B}}=3250 \pm 40$ $\left.\mathrm{M}^{-1} \mathrm{~s}^{-1} ; k_{-6}=3100 \pm 100 \mathrm{M}^{-1} \mathrm{~s}^{-1}\right)$. 
It should be emphasized that this saturation is seen only well above the experimental conditions used to derive the unitless $K_{5}$ and $K_{6}$, from which the thermochemical data are derived ( $c f$., Figure 3). The hydrogen-bonded adducts are not present in significant concentrations under typical measurement conditions. As further confirmation, we note that the optical spectrum of $\mathbf{F e}^{\text {III }}$ (Hbip) appears to be sensitive to the hydrogen bonding environment, as the $\lambda_{\max }$ shifts from $636 \mathrm{~nm}$ to $610 \mathrm{~nm}$ upon addition of $\mathrm{MeOH}$ to $1.17 \mathrm{M}\left(\left[\mathbf{F e}^{\mathrm{III}}(\mathbf{H b i p})\right]=86 \mu \mathrm{M}\right)$. This spectral shift is not observed for Fe $\mathbf{F e}^{\mathrm{III}}$ (Hbip) at [TEMPO-H] up to $\sim 0.12 \mathrm{M}$, although such a shift is observed when [TEMPO-H] $\geq 0.4 \mathrm{M}$. Solutions of pure $\mathbf{F e}^{\mathbf{I I I}}(\mathbf{H b i p})$ and

$\mathbf{F e}^{\mathrm{III}}(\mathbf{H b i m})$ follow Beer's Law over the accessible concentration and wavelength ranges $(0.06$ $-0.8 \mathrm{mM}, 400-750 \mathrm{~nm}$ ), indicating that the iron complexes do not cluster in solution.

As additional confirmation of the unitless nature of the equilibrium constants (eq 7), the static equilibrium mixtures of reactions 5 and 6 have been diluted with $\mathrm{MeCN}$. No variation in the ratio of $\mathbf{F e}^{\mathbf{I I}}\left(\mathbf{H}_{2} \mathbf{L}\right) / \mathbf{F e}^{\mathrm{III}}(\mathbf{H L})$ is observed within error over a $40 \%$ change in volume (Figure $5)$. The red dashed line in Figure 5 shows the dependence predicted for a concentrationdependent equilibrium constant, as would be observed for instance if $K_{8 \mathrm{~A}}$ were very large (i.e. if all the $\mathbf{F e}^{\mathrm{III}}(\mathbf{H L})$ were complexed) and if what was measured was $K_{8 \mathrm{~B}}=k_{8 \mathrm{~B}} / k_{-8 \mathrm{~B}}$. The blue horizontal line shows the prediction for a unitless equilibrium constant (eq 7).

The equilibrium constant $K_{5}$ in acetonitrile is unaffected by the addition of tetrabutylammonium perchlorate $\left({ }^{n} \mathrm{Bu}_{4} \mathrm{NClO}_{4}\right)$ up to $0.17 \mathrm{M}$. This represents a change in ionic strength of approximately three orders of magnitude $\left(I=1.8 \times 10^{-4}-0.17 \mathrm{M}\right.$; Figure S9). The lack of an ionic strength dependence shows that there is no difference between the ion pairing of the reactants vs. the products. This further indicates that eqs 5 and 6 are simple opposing bimolecular reactions with unitless equilibrium constants.

D. Solvent effects-Equilibrium constants have been determined in $\mathrm{CH}_{2} \mathrm{Cl}_{2}$ for $\mathbf{F e}^{\mathbf{I I}}\left(\mathbf{H}_{2} \mathbf{b i p}\right)+$ TEMPO (eq 5) and in acetone for $\mathbf{F e}^{\mathbf{I I}}\left(\mathbf{H}_{2}\right.$ bim) + TEMPO (eq 6). A wider range of solvents is precluded by the solubility and reactivity of the dicationic iron species. These experiments used the static equilibrium method described for $\mathrm{MeCN}$ above, yielding $K_{5 \mathrm{CH} 2 \mathrm{Cl} 2}=5.4 \pm 0.7$ and $K_{6 \mathrm{Me} 2 \mathrm{CO}}=(6.7 \pm 0.2) \times 10^{-4}$ (both at $298 \mathrm{~K}$ ). There is very little change in the absorption spectra of TEMPO, $\mathbf{F e}^{\mathbf{I I}}\left(\mathbf{H}_{2} \mathbf{L}\right)$, and $\mathbf{F e}^{\mathrm{III}}(\mathbf{H L})$ as a function of solvent, 36 and the equilibrium mixtures qualitatively appear very similar to those in $\mathrm{MeCN}$.

Quantitatively, $K_{5 \mathrm{CH} 2 \mathrm{Cl} 2}$ and $K_{6 \mathrm{Me} 2 \mathrm{CO}}$ are each approximately three times larger than the $K$ 's in $\mathrm{MeCN}$ at $298 \mathrm{~K}$. The temperature dependences of these equilibria give $\Delta H^{\circ}$ and $\Delta S^{\circ}$ values that are within error of those determined in $\mathrm{MeCN}$, as summarized in Table 4 and shown in the van't Hoff plots in Figure 3 ( $K_{5}$ in $\mathrm{CH}_{2} \mathrm{Cl}_{2}$ in green, $K_{6}$ in acetone in black). Thus, solvation and hydrogen bonding to solvent cannot fully account for the observed entropy effects in these reactions. The $\Delta S^{\circ}$ varies slightly with solvent, but still remains large and negative in all cases.

\section{Comparison with an electron transfer reaction}

The electron transfer (ET) reaction between $\mathbf{F e}^{\mathbf{I I I}}\left(\mathbf{H}_{2}\right.$ bim) and 1,2,3,4,5-pentamethylferrocene $(\mathrm{CpCp} * \mathrm{Fe}$ ) (eq 10) has been studied in $\mathrm{MeCN}$, in order to compare the entropy changes for ET vs. HAT. Addition of $0-0.3$ equiv CpCp*Fe to a $2 \mathrm{mM}$ solution of $\mathbf{F e}^{\mathrm{III}}\left(\mathbf{H}_{\mathbf{2}} \mathbf{b i m}\right)$ yields $\mathbf{F e}^{\mathbf{I I}}\left(\mathbf{H}_{2}\right.$ bim $)$ and the distinctive $[\mathrm{CpCp} * \mathrm{Fe}]^{+}$

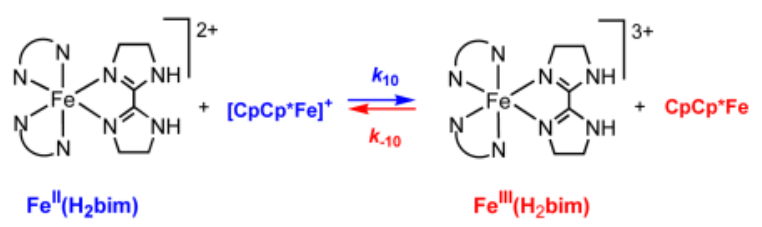


ion $\left(\lambda_{\max }=740 \mathrm{~nm}, \varepsilon=353 \mathrm{M}^{-1} \mathrm{~cm}^{-1}\right) .{ }^{37}$ The conversion is not quantitative, and equilibrium is established between the four species present (Figure 6A). The large excess of $\mathbf{F e} \mathrm{e}^{\mathrm{III}}\left(\mathrm{H}_{2}\right.$ bim $)$ prevents direct quantification of all but $[\mathrm{CpCp} * \mathrm{Fe}]^{+}$by optical spectroscopy; however, based on the starting conditions, the equilibrium constant for the process can be extracted (analogous to the analysis for eq 6) as $K_{10}(298 \mathrm{~K})=5.5 \pm 0.8$ (Figure S10). This is in good agreement with the equilibrium constant of $\sim 5$ predicted from the difference in redox potentials, $\left(E_{1 / 2}\left(\mathbf{F e}^{\mathrm{III}}\left(\mathbf{H}_{2} \mathbf{b i m}\right)\right)=-0.31 \pm 0.05 \mathrm{~V} ;{ }^{27} E^{\circ}\left([\mathrm{CpCp} * \mathrm{Fe}]\left[\mathrm{ClO}_{4}\right]\right)=-0.272 \pm 0.003\right.$ $\left.\mathrm{V} ;{ }^{38} \ln K_{10}=1.6 \pm 1.9\right) .{ }^{39}$ All ET reactions were done at a constant ionic strength, 0.09 $\mathrm{M}^{n} \mathrm{Bu}_{4} \mathrm{NClO}_{4}$. The equilibrium is temperature dependent and van't Hoff analysis (285-329 K) yields $\Delta H^{\circ}{ }_{10}=-6.0 \pm 0.9 \mathrm{kcal} \mathrm{mol}^{-1}$ and $\Delta S^{\circ}{ }_{10}=-17 \pm 3 \mathrm{cal} \mathrm{mol}^{-1} \mathrm{~K}^{-1}$ (Figure 6).

The overall entropy change for this outer-sphere electron transfer reaction $\left(\Delta S^{\circ}{ }_{10}\right)$ can be described in terms of the component half-reaction entropies $\Delta S^{\circ}{ }_{\mathrm{CpCp}} * \mathrm{Fe}$ and $\Delta S^{\mathrm{o}} \mathrm{Fe}(\mathrm{H} 2 \mathrm{bim}) / \mathrm{ET}$ (eq 11). ${ }^{40}$ For CpCp*Fe ${ }^{+/ 0}, \Delta S^{\circ} \mathrm{CpCp}^{*} \mathrm{Fe}=11.7 \pm 0.5 \mathrm{cal} \mathrm{mol}^{-1} \mathrm{~K}^{-1}\left(0.1 \mathrm{M}^{n} \mathrm{Bu}_{4} \mathrm{NClO}_{4}\right.$ in $\mathrm{MeCN}$ ) as determined by Noviandri and coworkers using the temperature dependence of the formal potential. ${ }^{38}$ This, in

$$
\Delta S_{10}^{\circ}=\Delta S_{\mathrm{CpCp} * \mathrm{Fe}}^{\circ}-\Delta S_{\mathrm{Fe}(\mathrm{H} 2 \mathrm{bim}) / \mathrm{ET}}^{\circ}
$$

combination with our measurement of $\Delta S^{\circ}{ }_{10}$, yields $\Delta S^{\circ} \mathrm{Fe}(\mathrm{H} 2 \mathrm{bim}) / \mathrm{ET}=29 \pm 3 \mathrm{cal} \mathrm{mol}^{-1} \mathrm{~K}^{-1}$ (Scheme 1). This is both the same sign and magnitude as the HAT reaction entropies found above (note that by convention, the ET half-reaction is written as a reduction, opposite to the iron redox couples in eqs 5 and 6 ).

Calculations-Computations have been performed on a version of reaction 6 where two of the iron ligands have been simplified to 1,4-diazabutadiene and TEMPO-H has been reduced to $\mathrm{NH}_{2} \mathrm{OH}$ (eq 12). The reactants and products were treated as gas-phase hydrogen-bonded adducts. The product has a dicationic $\mathrm{Fe}^{\mathrm{III}}$-Hbim moiety with a spin of $5 / 2$ which is hydrogenbonded to the zero charge and spin $\mathrm{HONH}_{2}$ molecule. The reactant is a $\mathrm{Fe}^{\mathrm{II}}-\mathrm{H}_{2}$ bim unit with the same $2+$ charge and a nominal spin of 2 (high-spin $\mathrm{d}^{6}$ ), coupled to a neutral, spin $1 / 2,{ }^{\circ} \mathrm{ONH}_{2}$ radical. Ferromagnetic

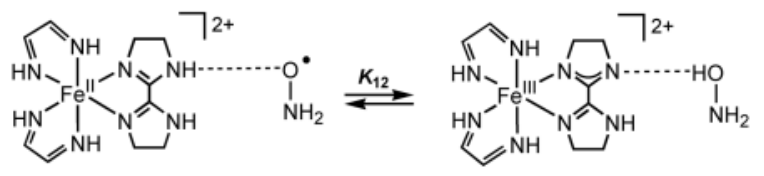

coupling has been assumed, both for ease of computation and to give a spin-allowed reaction, so that the reactant has an overall spin of $5 / 2$. In this model, the reaction is a 'simple' hydrogen transfer, $\mathrm{N}-\mathrm{H} \cdots{ }^{\circ} \mathrm{O} \leftrightarrows \mathrm{N}^{\bullet} \cdots \mathrm{H}-\mathrm{O}$, with concomitant structural reorganization of the reagents.

Initial calculations using the B3LYP functionals in DFT with a 6-31G* basis set failed to reproduce the observed ground-state for $\mathbf{F e}^{\mathbf{I I I}}$ (Hbim). Instead these predicted a d ${ }^{6} S=2 \mathrm{Fe}^{\mathrm{II}}$ center coupled to an Hbim radical, with spin $1 / 2$ on the deprotonated ring. Considering only the active $\mathrm{N}=\mathrm{C}-\mathrm{NH}$ part of the ligand, the calculations show a $\pi$-allyl-type radical, $\mathrm{N}=\mathrm{C}-\dot{\mathrm{N}}: \leftrightarrow \dot{\mathrm{N}}$ $\mathrm{C}=\mathrm{N}$ :. That is, $\mathrm{H}^{+}$was apparently removed from the $\mathrm{N}$ sigma lone pair but the $e^{-}$was removed from the $\pi$ system. This model calculation gave a predicted entropy decrease of only 5 cal $\mathrm{K}^{-1} \mathrm{~mol}^{-1}$, which was associated mostly with changes in vibrational frequencies.

Ordinarily, DFT results are more reliable than UHF results for transition metal complexes. In view of the failure of DFT, however, we resorted to a UHF calculation with the same basis set. 
This gave a wave function in qualitative agreement with the experimental conclusions. The $\mathrm{Fe}$ center in the reactant had a Mulliken population of 4.0 net spin-up electrons and a total charge of 1.6, in agreement with the $\mathrm{d}^{6} \mathrm{~S}=2 \mathrm{Fe}^{\mathrm{II}}$ label. The product $\mathrm{Fe}$ center was computed to have 4.7 net spin-up electrons and a total charge of 2.1 , in fair agreement with a d ${ }^{5} \mathrm{~S}=5 / 2 \mathrm{Fe}^{\mathrm{III}}$ description. There was a small 0.2 net spin-up on the Hbim group and a change in its net charge of -0.6 electrons. Thus this model predicts a coupled $\left(e^{-}, \mathrm{H}^{+}\right)$transfer of a proton from the $\mathrm{H}_{2}$ bim and an electron from the Fe center.

Associated with this oxidation of the $\mathrm{Fe}$, deprotonation of $\mathrm{H}_{2}$ bim, and reduction of the ${ }^{\circ} \mathrm{ONH}_{2}$, there is a significant change in bond lengths. The Fe-N distance in the ring from which the $\mathrm{H}$ is removed shortens by $0.27 \AA$ and all the other Fe-N distances shorten by 0.16 to $0.08 \AA$. These are in the same direction but somewhat larger than the differences between the solid state structures of high-spin $\mathbf{F e}^{\mathbf{I I}}\left(\mathbf{H}_{2}\right.$ bim $)$ and high-spin $\mathbf{F e}^{\mathbf{I I I}}(\mathbf{H b i m}): \Delta d(\mathrm{Fe}-\mathrm{N})=$ $0.17 \AA$ for the deprotonating ring and an average of $0.07 \AA$ for the others (Table 1). ${ }^{27}$ In the active $\mathrm{N}=\mathrm{C}-\mathrm{NH}$ part of $\mathrm{H}_{2}$ bim, the $\mathrm{N}=\mathrm{C}$ double bond is calculated to lengthen from 1.28 to $1.37 \AA$ ( 1.27 to $1.33 \AA$ in the solid state structures) while the $\mathrm{N}-\mathrm{C}$ single bond shortens from 1.33 to $1.26 \AA$ when the $\left(e^{-}, \mathrm{H}^{+}\right)$pair is removed $(1.34-1.31 \AA$ in the solids). These bond length differences lead to extensive changes in many of the low frequency vibrational modes.

These changes in bonding lead to a predicted entropy decrease, $\Delta S^{\circ}{ }_{12}=-18.7 \mathrm{cal} \mathrm{mol}^{-1}$ $\mathrm{K}^{-1}$. The calculation is done with constant spin and mass; therefore this entropy can only come from rotational and vibrational sources. The calculation shows that the contribution from the change in moment of inertia is small, as would be expected from a reaction in which the primary chemical change is the $\sim 1 \AA$ movement of a hydrogen atom. Changes in vibrational frequencies account for $18.4 \mathrm{cal} \mathrm{mol}^{-1} \mathrm{~K}^{-1}$ of the $\Delta S^{\circ}$ in this system. This is spread over the 30 or so modes with frequencies $h v$ on the order of $k T\left(207 \mathrm{~cm}^{-1}\right.$ at $\left.298 \mathrm{~K}\right)$. These are bending and torsional vibrations, not stretches (which are at much higher frequency) where each mode contributes between $0.5-6 \mathrm{cal} \mathrm{mol}^{-1} \mathrm{~K}^{-1}$ to the total entropy. Calculated vibrational frequencies and their entropic contributions are given in Tables S2 and S3. It should be noted that this calculation neglects possible electronic contributions to the entropy, although these are expected to be small. If the reactant pair is antiferromagnetically coupled to give a total spin of $S=3 / 2$ (which would make the overall reaction forming $\mathrm{S}=5 / 2$ high spin $\mathrm{Fe}^{\mathrm{III}}$ spin-forbidden), there would be a spin contribution to the entropy of $+0.8 \mathrm{cal} \mathrm{mol}^{-1} \mathrm{~K}^{-1}\left(\mathrm{~T} \Delta S=0.2 \mathrm{kcal} \mathrm{mol}^{-1}\right.$ at $\left.298 \mathrm{~K}\right)$. 41 There could also be a small entropy contribution from low-lying electronic states of the high spin $\mathrm{d}^{6}$ configuration.

\section{Discussion}

\section{Overview of hydrogen atom transfer entropies}

A hydrogen atom transfer reaction (eq 13) can be considered as the sum of two half reactions (e.g., eq 14) by analogy to electron transfer

$$
\begin{aligned}
& \mathrm{A}-\mathrm{H}+\mathrm{B}^{\bullet} \rightarrow \mathrm{A}^{\bullet}+\mathrm{H}-\mathrm{B} \quad \Delta G^{\circ}{ }_{13}, \Delta H^{\circ}{ }_{13}, \Delta S^{\circ}{ }_{13} \\
& \mathrm{~A}-\mathrm{H} \rightarrow \mathrm{A}^{\bullet}+\mathrm{H}^{\bullet} \quad \text { BEFE,BDE }
\end{aligned}
$$

processes. The half reaction is the definition of the bond dissociation free energy (BDFE) and bond dissociation enthalpy (BDE). The general assumption that the entropies of $\mathrm{AH}$ and $\mathrm{A}^{*}$ are very similar (eq 15), has the corollary that for HAT reactions the overall entropy change should be small, $\Delta S^{\circ}{ }_{13} \approx 0$. Equation 15 is an implicit assumption in the widely accepted thermochemical cycles used to derive BDEs from acidity $\left(\mathrm{p} K_{\mathrm{a}}\right)$ and redox potential $\left(E_{1 / 2}\right)$, as discussed below. Eq 15 


$$
S^{\circ}(\mathrm{AH}) \approx S^{\circ}\left(\mathrm{A}^{\bullet}\right)
$$

will not be strictly accurate because $\mathrm{AH}$ and $\mathrm{A}^{\bullet}$ have different moments of inertia and different spin states, but these are in most cases small effects. For instance, the (molar) entropy resulting from a change from spin 0 to spin $1 / 2$ is $R \ln (2)$ or $1.4 \mathrm{cal} \mathrm{mol}^{-1} \mathrm{~K}^{-1}\left(\mathrm{~T} \Delta S^{\circ}=0.42 \mathrm{kcal} \mathrm{mol}^{-1}\right)$. Even for organic systems in which free or slightly hindered rotations in AH become essentially 'frozen' in $\mathrm{A}^{\bullet}$, entropy changes still appear to be small. For the prototypical example of toluene versus benzyl radical, $\Delta S^{\circ}$ is only $-0.47 \mathrm{cal} \mathrm{mol}^{-1} \mathrm{~K}^{-1}$ (Table 5). The entropy data that are available, for small organic and main-group species in the gas phase, provide support for eq 15. $\left|S^{\circ}\left(\mathrm{A}^{\bullet}\right)_{\mathrm{g}}-S^{\circ}(\mathrm{AH})_{\mathrm{g}}\right|$ is $<5.2 \mathrm{cal} \mathrm{mol}^{-1} \mathrm{~K}^{-1}$ for the various molecules in Table 5. This corresponds to a change in an equilibrium constant of less than a factor of 14 , or $\leq 1.5 \mathrm{kcal}$ $\mathrm{mol}^{-1}$ in $\Delta G^{\circ}$ at $298 \mathrm{~K}$.

For HAT reactions in solution, the entropy changes are small when the analogous gas-phase reaction has $\Delta S^{\circ}{ }_{13} \approx 0$ and the entropies of solvation are comparable (eq 16). A few

$$
\Delta S_{\text {solv }}^{\circ}[\mathrm{AH}]+\Delta S_{\text {solv }}^{\circ}\left[\mathrm{B}^{\bullet}\right] \approx \Delta S_{\text {solv }}^{\circ}[\mathrm{BH}]+\Delta S_{\text {solv }}^{\circ}\left[\mathrm{A}^{\bullet}\right]
$$

entropies for HAT reactions have been reported for organic molecules in solution, which support this assumption, $\Delta S^{\circ}{ }_{13}$ (solution) $\approx 0$. For example, the reaction between galvinoxyl radical and 2,4,6-tri-tert-butylphenol is thermodynamically uphill $\left(\Delta G^{\mathrm{o}}=2.6 \mathrm{kcal} \mathrm{mol}{ }^{-1}\right)$ in toluene and has $\Delta S^{\mathrm{o}}=-0.7 \pm 0.6 \mathrm{cal} \mathrm{mol}^{-1} \mathrm{~K}^{-1.46}$ The related hydrogen atom transfer between the $\alpha$-tocopherol radical and phenothiazine has $\Delta S^{\circ}=-1.2 \pm 3.0$ in benzene. ${ }^{47}$ There are even fewer examples of related inorganic systems in solution where the ground-state entropy change has been determined. Norton and co-workers have calculated $\Delta S^{\circ}(\mathrm{AH})-\Delta S^{\circ}\left(\mathrm{A}^{\bullet}\right)=-2.68 \mathrm{cal}$ $\mathrm{mol}^{-1} \mathrm{~K}^{-1}$ for $\mathrm{CpCr}(\mathrm{CO})_{3} \mathrm{H}{ }^{23 \mathrm{~b}}$ Wayner and Parker used a series of thermochemical cycles to conclude that $\Delta S^{\mathrm{o}}{ }_{13} \approx 0$ for a wide range of transition metal hydrides. ${ }^{23 \mathrm{a}, 48}$ In sum, previously published studies of HAT reactions support the common assumption that $\Delta S^{\circ}{ }_{13}$ is close to zero, and therefore that $\Delta G_{\mathrm{HAT}}^{\circ} \approx \Delta H_{\mathrm{HAT}}^{\mathrm{o}}=\Delta \mathrm{BDE}$.

\section{Origin of the large entropy of the $\mathrm{Fe}^{\mathrm{Il}}\left(\mathrm{H}_{2} \mathrm{~L}\right)$ reactions}

The reactions of $\mathbf{F e}^{\mathbf{I I}}\left(\mathbf{H}_{2} \mathbf{b i p}\right)$ and $\mathbf{F e}^{\mathbf{I I}}\left(\mathbf{H}_{2}\right.$ bim) with TEMPO contradict the common assumption that entropy changes are not significant in HAT reactions. These reactions have $\Delta S^{\circ} \approx-30 \mathrm{cal} \mathrm{mol}^{-1} \mathrm{~K}^{-1}$, the negative sign indicating that $\mathbf{F e} \mathrm{e}^{\mathbf{I I I}} \mathbf{( H L )}+\mathrm{TEMPO}-\mathrm{H}$ is the more ordered side of eqs 5 and 6 . A variety of possible origins of this entropy change are considered in the sections below.

\section{Translational entropy}

(a) Molecularity: For a bimolecular reaction, $-30 \mathrm{cal} \mathrm{mol}^{-1} \mathrm{~K}^{-1}$ would be a typical entropy of activation, $\Delta S^{\ddagger} .35$ This is due to the loss of translational entropy required to bring two freely diffusing reactants together. A similar value of the ground state entropy, $\Delta S^{\circ}$, would be expected for a reaction where two separate reactants combine to form one product. For reactions 5 and 6 , however, a number of lines of evidence indicate that there are equal numbers of reactants and products. The reactions obey simple second-order kinetics under the conditions where the $\Delta S^{\circ}$ is determined, showing saturation kinetics only at high [TEMPO-H]. Similar values for $\Delta S^{\circ}{ }_{5}$ and $\Delta S^{\circ}{ }_{6}$ are found for both systems measurements despite the difference in $K_{8 \mathrm{~A}}, 3.1 \mathrm{M}^{-1}$ and $57 \mathrm{M}^{-1}$ for eqs 5 and 6 respectively. If there were a change in the number of molecules during the reaction, the position of equilibrium would be a function of concentration, but no such dependence is observed in static experiments ( $c f$., Figure 5). Thus a change in translation entropy between the reactants and products is not the origin of the large $\left|\Delta S^{\circ}\right|$ 
(b) Ion pairing: The iron reagents in eqs 5 and 6 are charged and therefore have counterions that could be ion paired to different extents under different conditions. A change in the ion pairing between reactants and products could also cause a change in the molecularity of the reactions and therefore the reaction entropy. However, there is no ionic strength dependence in $\mathrm{MeCN}$, over four orders of magnitude in $I$. In addition, the same entropy change within error is observed for eq 5 in both $\mathrm{MeCN}$ and $\mathrm{CH}_{2} \mathrm{Cl}_{2}$, although ion pairing is much stronger in the latter solvent.

(c) Solvent effects/hydrogen bonding: Different solvation of the reactants and products is another possible source of the observed ground-state entropy change. Non-specific solvation of charged ions involves the organization of polar solvent molecules and has significant entropic effects. In reactions 5 and 6, the iron reactants $\left(\mathbf{F e}^{\mathbf{I I}}\left(\mathbf{H}_{2} \mathbf{L}\right)\right)$ and products $\left(\mathbf{F e}^{\mathrm{III}}(\mathbf{H L})\right.$ ) have the same 2+ charge and are almost the same size (despite the change in $d$ (Fe-N) of $\sim 0.1 \AA$ ), so their solvation (and ion pairing) should be very similar. In general, for reactions that involve only transfer of a neutral $\mathrm{H}$ atom, there are likely to be only very small changes in non-specific solvation.

There could, however, be significant changes in the interactions of the reactants with particular solvent molecules, for instance different hydrogen bonding. Reactions of phenols show very large kinetic solvent effects because of the ArO-H• • • solvent hydrogen bond, which is not present at the transition state. ${ }^{49}$ In the absence of hydrogen bonding effects, HAT reactions are often insensitive to solvent: the rate constants for cumyloxyl radical plus cyclohexane are the same within $10 \%$ in $\mathrm{CCl}_{4}, \mathrm{C}_{6} \mathrm{H}_{6},{ }^{t} \mathrm{BuOH}, \mathrm{MeCN}$, and $\mathrm{AcOH} .{ }^{50}$ Reactions 5 and 6 are almost this insensitive to solvent. The equilibrium constants increase by only a factor of $\sim 3$ $\left(\Delta \Delta G^{\circ} \approx 0.6 \mathrm{kcal} \mathrm{mol}^{-1}\right.$ ) on switching from $\mathrm{MeCN}$ to $\mathrm{CH}_{2} \mathrm{Cl}_{2}$ (for $K_{5}$ ) or $\mathrm{MeCN}$ to acetone (for $K_{6}$ ). The same ground state entropy changes are observed in all the solvents, within experimental error (Table 4). $\mathrm{MeCN}$, acetone, and $\mathrm{CH}_{2} \mathrm{Cl}_{2}$ have quite different polarities (dielectric constants of 37.5, 20.7, and 8.9 respectively 51 ), so differential non-specific solvation is not important to these reactions. Nor are changes in hydrogen bonding significant, since $\mathrm{CH}_{2} \mathrm{Cl}_{2}$ is a much poorer hydrogen-bond acceptor than acetone or MeCN (with $\beta_{2(s)}^{H}$ values of $0.05,0.49$, and 0.44 , respectively in the Abraham scale favored for phenol reactions.) 49,52 None of these solvents is a good hydrogen-bond donor.

In sum, the large magnitude of the entropies for reactions 5 and 6 are not due to translational entropy from different numbers of reactant and product molecules, nor to different amounts of ion pairing, nor to solvent effects. Since organic HAT half reactions have not been observed to have large entropies, the unusual $\Delta S^{\circ}$ for these reactions is very likely a property of the iron redox couples (the iron HAT half-reactions).

(d) Iron spin equilibria: In our preliminary report of reaction 5 and its analysis with Marcus theory, we speculated that the large $\left|\Delta S^{\circ}\right|$ could be due to high-spin/low-spin equilibria for

$\mathbf{F e}^{\mathrm{II}}\left(\mathbf{H}_{2}\right.$ bip) and $\mathbf{F e}^{\mathrm{III}}(\mathbf{H b i p}) .{ }^{16}$ Both of these compounds are mixtures of high- and low-spin forms over the accessible temperature range in $\mathrm{MeCN}$ solution. $\mathbf{F e}^{\mathbf{I}}\left(\mathbf{H}_{2} \mathbf{b i p}\right)$ in $\mathrm{MeCN}$ at 298 $\mathrm{K}$ is $88 \%$ high-spin and $12 \%$ low-spin, and spin interconversion has $\Delta H^{\circ}{ }_{\text {spin }}=-5.1 \pm 0.5 \mathrm{kcal}$ $\mathrm{mol}^{-1}$ and $\Delta S^{\circ}$ spin $=-21 \pm 2 \mathrm{cal} \mathrm{mol}^{-1} \mathrm{~K}^{-1.25} \mathbf{F e}^{\mathrm{III}}$ (Hbip) is $16 \%$ high-spin and $84 \%$ low-spin in MeCN at $298 \mathrm{~K}$, with $\Delta H^{\circ}$ spin $=-1.9 \pm 0.7 \mathrm{kcal} \mathrm{mol}^{-1}$ and $\Delta S^{\circ}$ spin $=-3 \pm 2 \mathrm{cal} \mathrm{mol}^{-1}$ $\mathrm{K}^{-1}$ (at $\left.298 \mathrm{~K}\right) .{ }^{25}$ Measurements of reaction 6 were done to test this hypothesis, because $\mathbf{F e}^{\mathrm{II}_{(}}\left(\mathbf{H}_{2} \mathbf{b i m}\right)$ and $\mathbf{F e}^{\mathrm{III}}(\mathbf{H b i m})$ are fully high-spin under all of our conditions. The result that the same large entropy change is observed for both the $\mathrm{H}_{2}$ bip and $\mathrm{H}_{2}$ bim systems rules out spin equilibria as the cause of the $\Delta S^{\circ}$. 
(e) Vibrational entropy of the iron complexes: While spin equilibria are not the origin of the $\Delta S^{\circ} \approx-30 \mathrm{cal} \mathrm{mol}^{-1} \mathrm{~K}^{-1}$ for reactions 5 and 6 , it is interesting that there is a similar entropy change for high-spin to low-spin transition for $\mathbf{F e}^{\mathbf{I I}}\left(\mathbf{H}_{2} \mathbf{b i p}\right),-21 \mathrm{cal} \mathrm{mol}^{-1} \mathrm{~K}^{-1.25}$ Such large spin-change entropies are common for iron(II) compounds and are due primarily to vibrational entropy $\left(\Delta S^{\mathrm{o}}{ }_{\mathrm{vib}}\right){ }^{28,54}$ The solvation and ion-pairing properties are very similar for high- vs. low-spin ions, and the electronic contribution to the entropy $\left(\Delta S_{\text {elec }}^{\mathrm{o}}\right)$ is small. In the absence of spin-orbit coupling, conversion of a ${ }^{5} \mathrm{~T}_{2 \mathrm{~g}}$ state to a ${ }^{1} \mathrm{~A}_{1 \mathrm{~g}}$ state has $\Delta S^{\mathrm{o}}$ elec $=-5.4 \mathrm{cal} \mathrm{mol}^{-1}$ $\mathrm{K}^{-1} .53$

Vibrational entropy $\left(\Delta S_{\text {vib }}^{\text {o }}\right.$ ) has been extensively discussed both for spin-equilibria 28,54 and for electron transfer couples. ${ }^{55,56}$ Sorai and Seki were the first to connect changes in metalligand vibrations with entropies for spin-crossover that were substantially larger than the electronic entropy from the change in spin-multiplicities. ${ }^{57}$ As illustrated by Richardson and Sharpe (for harmonic vibrations), ${ }^{55}$ the major contributors are skeletal vibrations at low energy $\left(\approx k \mathrm{~T}, 207 \mathrm{~cm}^{-1}\right.$ at $\left.298 \mathrm{~K}\right)$ that change frequency between reactions and products. Our calculations on eq 12 , a model for reaction 6 , follow this general pattern. There are approximately 30 vibrations in both the reactant and the product that contribute between 0.5 and $6 \mathrm{cal} \mathrm{mol}^{-1} \mathrm{~K}^{-1}$ to $\Delta S^{\circ}{ }_{12}$. These are low frequency ( 207 to $330 \mathrm{~cm}^{-1}$ ) torsion and bending modes. Summing over all the vibrational modes, the difference between the reactants and products gives $\Delta S^{\mathrm{o}}{ }_{12}=-18.4 \mathrm{cal} \mathrm{mol}^{-1} \mathrm{~K}^{-1}$ from the UHF/6-31G* calculations, reasonable agreement given that the calculations were done at a moderate level of theory (UHF) on a model system, in the gas phase. In essence, the $\mathrm{Fe}^{\mathrm{II}}$ complex is 'floppier' and has more lower frequency modes as compared to the $\mathrm{Fe}^{\mathrm{III}}$ complex.

The $\mathbf{F e}^{\mathrm{III}}\left(\mathbf{H}_{2}\right.$ bim $) \rightarrow \mathbf{F e}^{\mathrm{II}}\left(\mathbf{H}_{2}\right.$ bim $)$ electron transfer couple shows a similarly large entropy of $\Delta S^{\circ} \mathrm{Fe}(\mathrm{H} 2 \mathrm{bim}) / \mathrm{ET}=29 \pm 3 \mathrm{cal} \mathrm{mol}^{-1} \mathrm{~K}^{-1}$, as determined from the solution ET equilibrium between $\mathbf{F e}^{\mathrm{III}}\left(\mathbf{H}_{2}\right.$ bim $)$ and $\mathrm{CpCp} * \mathrm{Fe}$. This value is the same within error as the $\Delta S^{\mathrm{o}}$ measured for the overall HAT reactions in eqs 5 and 6 (the sign of $\Delta S^{\circ} \mathrm{Fe}(\mathrm{H} 2 \mathrm{bim}) / \mathrm{ET}$ is opposite to that of $\Delta S^{\circ}{ }_{5}$ and $\Delta S^{\circ}{ }_{6}$ because ET reactions are written as reductions by convention). The close numerical agreement between HAT and ET entropies is in part fortuitous, since the ET reaction involves changes in overall charge and therefore solvation. Electron transfer half-reaction entropies for $\mathrm{Fe}^{\mathrm{III}} / \mathrm{Fe}^{\mathrm{II}}$ redox couples are typically found to be $15-30 \mathrm{cal} \mathrm{mol}^{-1} \mathrm{~K}^{-1}$ in organic solvents (excepting those with an accompanying spin-change). ${ }^{55,56}$ For example, $\Delta S^{\mathrm{o}}{ }_{\mathrm{ET}}$ for low-spin $\left[\mathrm{Fe}\left\{\mathrm{B}(\mathrm{pz})_{4}\right\}_{2}\right]^{+/ 0}$ is $19 \pm 1 \mathrm{cal} \mathrm{mol}^{-1} \mathrm{~K}^{-1}$ in $\mathrm{MeCN}\left(\left[\mathrm{B}(\mathrm{pz})_{4}\right]^{-}=\right.$tetrakis(pyrazol-1yl)borate). ${ }^{56 \mathrm{a}}$ As emphasized for $\left[\mathrm{M}\left(\mathrm{OH}_{2}\right)_{6}\right]^{3+/ 2+}$ ions in aqueous solution, hydrogen bonding can increase half-reaction entropies, but for larger cations in organic solvents the differences in solvation are small and $\Delta S^{\mathrm{o}}{ }_{\mathrm{ET}}$ is dominated by $\Delta S_{\text {vib. }}^{\mathrm{o}}{ }^{55}$ While these electron transfer reactions are not directly comparable to our HAT reactions because ET involves a change in charge, the parallel is clear. The $\mathrm{Fe}^{\mathrm{III}}$ complexes are more rigid and have fewer low frequency vibrational modes than $\mathrm{Fe}^{\mathrm{II}}$ analogues for both ET and HAT. The large ET entropies support the conclusion that there are substantial vibrational entropy changes for the $\mathrm{Fe} e^{\mathrm{III}} / \mathrm{Fe}^{\mathrm{II}}$ couples in this system, and that $\Delta S^{\circ}$ and $\Delta S^{\circ}{ }_{6}$ deviate from zero because of the entropy of the iron HAT half-reactions.

\section{Broader implications}

(a) Generality of $\mathbf{S}^{\circ}(\mathbf{A H}) \neq \mathbf{S}^{\circ}\left(\mathbf{A}^{\circ}\right)$ - The entropy assumption $S^{\circ}(\mathrm{AH}) \approx S^{\circ}\left(\mathrm{A}^{\circ}\right)$ (eq 15) appears to hold for organic molecules. This is based on the gas phase data in Table 5 and on well-benchmarked solution studies with a wide range of organic compounds. ${ }^{20-22}$ This assumption fails for the iron complexes due to their large number of low-frequency vibrational modes that change upon oxidation or reduction by HAT. It appears that organic compounds have fewer low frequency modes $(v \approx k \mathrm{~T})$ and/or that few of these modes change substantially upon gain/loss of $\mathrm{H}^{*}$, perhaps due to more localized covalent bonding in organic species 
compared to more dative bonding in coordination complexes. More studies are needed to determine how general these large entropy changes are for coordination compounds. At the present time, we can only speculate that HAT entropy changes of vibrational origin should often parallel entropies for related electron transfer half-reactions.

Large entropies are common for $\mathrm{Fe}^{\mathrm{III}} / \mathrm{Fe}^{\mathrm{II}}$ redox couples and are smaller for second and third row transition metals, as in the $\mathrm{Ru}^{\mathrm{III}} / \mathrm{Ru}^{\mathrm{II}}$ redox couples. ${ }^{56 \mathrm{e}, \mathrm{j}}$ In general, half-reaction entropies will be large for cases where the orbital occupancy of strongly bonding or antibonding orbitals changes upon reduction of the metal center. This is most noticeable in cases where the spinstate changes as well as the oxidation state, the classic example being low-spin $\mathrm{Co}$ III/high-spin $\mathrm{Co}^{\text {II. }}{ }^{55}$ Sutin and Weaver have also shown that $\Delta S^{\circ}$ for ET half-reactions is monotonic with the Marcus self-exchange reorganization energy, $\lambda$ (a free energy parameter). ${ }^{58}$ The innersphere component of the reorganization energy involves changes in equilibrium bond lengths. When the metal-ligand bonds become shorter and stronger, the whole complex becomes stiffer, shifting the more entropically relevant low frequency modes. This is parallel to the vibrational entropy basis for HAT entropies advanced here. If this ET/HAT parallel holds, the ET reorganization energies ${ }^{59}$ suggest that large entropy changes may be characteristic of many first row transition metal HAT couples. Even just considering $\mathrm{Fe}^{\mathrm{III}} / \mathrm{Fe}^{\mathrm{II}}$ couples, there are a large number of systems in coordination chemistry and in biology where the importance of entropy needs to be evaluated. In contrast, large entropic changes do not appear to be characteristic of organometallic systems, such as metal-carbonyl hydrides. ${ }^{23}$ Perhaps organometallic compounds resemble organic molecules in that the more covalent bonding leads to fewer low frequency modes that are affected by changes in the metal oxidation state.

(b) Bond dissociation enthalpies (BDEs) from $\mathrm{p} K_{\mathrm{a}}$ and $E_{1 / 2}$ values-In recent years, many groups including ours have used thermochemical cycles to determine $\mathrm{A}-\mathrm{H}$ bond dissociation enthalpies (BDEs) from measurements of acidity $\left(\mathrm{p} K_{\mathrm{a}}\right)$ and redox potential $\left(E_{1 / 2}\right)$. This approach was used early on by Wiberg, by Eberson, and by Breslow; ${ }^{19}$ its popularity dates to its development and extensive use by Bordwell and coworkers. ${ }^{20-24}$ One variation of the thermochemical approach is outlined in Scheme 2 and eq 17. The bond dissociation free energy (BDFE) of $\mathrm{A}-\mathrm{H}$ is given by its oxidation potential $\left(-E^{\circ}\left[\mathrm{AH}^{\bullet+/ 0}\right]\right)$, the acidity of the corresponding radical cation $\left(\mathrm{p} K_{\mathrm{a}}\left[\mathrm{AH}^{+\bullet}\right]\right.$ ), and the free energy to form a solvated hydrogen atom from the proton and electron in solution $\left(-\mathrm{F} E^{\circ}\left[\mathrm{H}^{+/ \circ}\right]\right)$. An analogous cycle involving $\mathrm{p} K_{\mathrm{a}}[\mathrm{AH}]$ and $E^{\circ}\left[\mathrm{A}^{0 /-}\right]$ is equivalent. Note that BDFE and BDE are used here as solution quantities, while by strict definition they should involve only gas-phase species. Bordwell and others have used Scheme 2 and related cycles to provide gas phase energetics, but this involves additional assumptions about solvation energies and is beyond the scope of this paper. 60

$$
\mathrm{BDFE}[\mathrm{AH}]=-\mathrm{F} E^{\circ}\left[\mathrm{HA}^{+\bullet / 0}\right]+2.303 \mathrm{RTp} K_{\mathrm{a}}\left[\mathrm{HA}^{\bullet+}\right]+C_{\mathrm{G}}
$$

The $\mathrm{p} K_{\mathrm{a}}$ and $E$ values are free energies measured in solution under a specific set of conditions (ideally the same conditions of solvent, temperature, electrolyte, ionic strength, etc.). The $\mathrm{nF} E^{\circ}\left(\mathrm{H}^{+/ \bullet}\right)$ term, while specific to these conditions and reference electrode, is valid for all A$\mathrm{H}$ compounds and is therefore termed a constant, $C_{\mathrm{G}}$ - the $\mathrm{G}$ implying free energy. However, such cycles are typically used to derive enthalpies (BDEs). The BDE is the BDFE plus the entropy change (eq 18). Equation 18 contains the difference between the entropies of $\mathrm{AH}$ and $\mathrm{A}^{\bullet}\left(\mathrm{T} \Delta S^{\circ}[\mathrm{AH}]-\mathrm{T} \Delta S^{\circ}\left[\mathrm{A}^{\circ}\right]\right)$. When this difference is close to zero - the entropy assumption of eq 15 above - eq 18 reduces to eq 19 where the enthalpy constant $C_{\mathrm{H}}$ includes only $-\mathrm{F} E^{\circ}$ $\left(\mathrm{H}^{+/ \bullet}\right)$ and $\mathrm{T} \Delta S\left[\mathrm{H}^{*}\right] . C_{\mathrm{H}}$ has been calculated from thermochemical values, as suggested here, or by fitting eq 19 to known BDEs. ${ }^{61}$ 


$$
\begin{gathered}
\mathrm{BDE}[\mathrm{AH}]=\mathrm{BDFE}[\mathrm{AH}]-\mathrm{T} \Delta \mathrm{S}^{\circ}[\mathrm{AH}]+\mathrm{T} \Delta \mathrm{S}^{\circ}\left[\mathrm{A}^{\bullet}\right]+\mathrm{T} \Delta \mathrm{S}^{\circ}\left[\mathrm{H}^{\bullet}\right] \\
\approx \mathrm{FE}^{\circ}\left(\mathrm{HA}^{0 /+\bullet}\right)+2.303 \mathrm{RT} \mathrm{T} K_{(\mathrm{HA} \bullet+)}+C_{\mathrm{H}} \\
C_{\mathrm{H}}=C_{\mathrm{G}}+\mathrm{T} \Delta S^{\circ}\left[\mathrm{H}^{\bullet}\right]
\end{gathered}
$$

For the iron HAT redox couples $\mathbf{F e}^{\mathrm{II}}\left(\mathrm{H}_{2} \mathbf{b i p}\right) / \mathrm{Fe}^{\mathrm{III}}(\mathrm{Hbip})$ and $\mathbf{F e}^{\mathrm{II}}\left(\mathrm{H}_{2} \mathbf{b i m}\right) / \mathbf{F e} \mathrm{e}^{\mathrm{III}}(\mathbf{H b i m})$, the assumption that $\left.S^{\circ}(\mathrm{AH}) \approx S^{\circ} \mathrm{A}^{\bullet}\right)$ does not hold. In MeCN, $S^{\circ}\left[\mathbf{F e}^{\mathrm{III}}(\mathbf{H L})\right]-S^{\circ}\left[\mathbf{F e}^{\mathrm{II}}\left(\mathbf{H}_{2} \mathbf{L}\right)\right]$ is $-30 \mathrm{cal} \mathrm{mol}^{-1} \mathrm{~K}^{-1}$ for each couple, corresponding to $T \Delta S^{\circ}=-9 \mathrm{kcal} \mathrm{mol}^{-1}$ in free energy at $298 \mathrm{~K}$. In previous papers we were unaware of this entropy effect and thus calculated erroneous BDEs using eq 19. The correct BDEs for $\mathbf{F e}^{\mathbf{I I}} \mathbf{p}\left(\mathbf{H}_{2} \mathbf{b i p}\right)$ and $\mathbf{F e}^{\mathbf{I I}}\left(\mathbf{H}_{2} \mathbf{b i m}\right)$ are $62 \pm 1$ and $67 \pm$ $2 \mathrm{kcal} \mathrm{mol}^{-1}$, respectively. Calorimetric studies are underway to obtain more direct measures of these values.

Since the measured $\mathrm{p} K_{\mathrm{a}}$ and $E_{1 / 2}$ values are free energies, it seems prudent to derive BDFEs and avoid assumptions about entropy, particularly for coordination complexes. For compounds where $S^{\circ}(\mathrm{AH}) \approx S^{\circ}\left(\mathrm{A}^{\circ}\right)$, as for organic species, the BDE will differ from the BDFE by $\Delta S^{\circ}$ $\left[\mathrm{H}^{\circ}\right]$ (eq 21). T $\Delta S^{\circ}\left[\mathrm{H}^{\circ}\right]$ varies only slightly with solvent: $4.62(\mathrm{MeCN}), 4.60$ (DMSO), 4.78 (toluene), $4.87 \mathrm{p}\left(1,2\right.$-dichloroethane), and $2.96\left(\mathrm{H}_{2} \mathrm{O}\right)$ at $298 \mathrm{~K}^{\text {in kcal mol}}{ }^{-1} .62$

$$
\text { when } S^{\circ}(\mathrm{AH}) \approx S^{\circ}\left(\mathrm{A}^{\bullet}\right), \quad \mathrm{BEFE}=\mathrm{BDE}-\mathrm{T} \Delta \mathrm{S}^{\circ}\left[\mathrm{H}^{\bullet}\right]
$$

(c) Implications for rate/driving force correlations for HAT reactions-The BellEvans-Polanyi correlation of activation energies with enthalpic driving force (eq 2) has been a cornerstone of organic radical chemistry for almost 70 years. $1 \mathrm{a}$ The results described here suggest that it should be formulated in free energy terms rather than enthalpic ones, correlating $\Delta G^{\ddagger}$ with $\Delta G^{\circ}$ or $\log k$ with $\log K_{\mathrm{eq}}$. We have previously described a number of correlations of $\log k$ with BDE for transition metal HAT reactions, including those of $\mathbf{F e}^{\mathbf{I I I}}(\mathbf{H b i m}){ }^{2,6,13,14}$ It is now clear that these were in effect correlations with BDFEs because the bond energies were derived from $\mathrm{p} K_{\mathrm{a}}$ and $E_{1 / 2}$ values. The bond energies used in these correlations should all be reduced by $5 \mathrm{kcal} \mathrm{mol}^{-1}$ to actually be BDFEs, due to the difference between $C_{\mathrm{G}}$ and $C_{\mathrm{H}}$ (eq 20). This correction does not affect the quality of our previous correlations because it does not affect the relative BDFEs; it only shifts the absolute scale. However, because of the entropy issues discussed here, if the accurate BDEs for $\mathbf{F e}^{\mathbf{I I}}\left(\mathbf{H}_{2} \mathbf{L}\right)$ [taking into account $S^{\circ}$

$\left.\left(\mathbf{F e}^{\mathbf{I I}}\left(\mathbf{H}_{2} \mathbf{L}\right)\right)-S^{\circ}\left(\mathbf{F e}^{\mathbf{I I I}}(\mathbf{H L})\right)\right]$ were used instead of the BDFEs, the correlations would not hold. Similarly, in our application of the Marcus cross relation to reactions of $\mathbf{F e}^{\mathbf{I I I}}(\mathbf{H b i m})$ and Fe $^{\text {III }}($ Hbip), the calculated equilibrium constants are accurate because they were derived from the $\mathrm{p} K_{\mathrm{a}}$ and $E_{1 / 2}$ values and the organic BDEs. 63

Most rate/driving force correlations in chemistry are linear free energy relations (LFERs) ${ }^{64}$, rather than correlations with enthalpies, so perhaps this result is not surprising. The long and varied success of the Polanyi relation is seen in this light as a special case, valid only when entropic effects are small. ${ }^{11 \mathrm{a}}$ Its success also supports the suggestion that entropic effects are minor for organic HAT reactions. In the more general case, for instance when metal complexes are involved, a free-energy based approach such as Marcus theory is more appropriate.

\section{Conclusions}

Hydrogen atom transfer (HAT) reactions from the iron complexes $\mathbf{F e}^{\mathbf{I I}}\left(\mathbf{H}_{2} \mathbf{b i p}\right)$ and $\mathbf{F e}^{\mathbf{I I}}\left(\mathbf{H}_{2} \mathbf{b i m}\right)$ to the organic radical TEMPO have large negative ground state entropy changes: $\Delta S^{\circ}=-30 \pm 2 \mathrm{cal} \mathrm{K}^{-1} \mathrm{~mol}^{-1}$ for both. These values are determined from equilibrium constants as a function of temperature using the van't Hoff equation. The $K_{\text {eq }}$ 's have been determined 
by static experiments and from the ratio of forward and reverse bimolecular rate constants. They are independent of concentration and ionic strength, indicating that the large entropy changes are not due to a change in the number of particles (i.e. not due to translational entropy). Similar $\Delta S^{\circ}$ values are observed in acetone and $\mathrm{CH}_{2} \mathrm{Cl}_{2}$, indicating that neither solvent effects nor hydrogen bonding are the origin of these entropy changes. The high-spin/low-spin equilibria of $\mathbf{F e}^{\mathbf{I I}}\left(\mathbf{H}_{2}\right.$ bip) and $\mathbf{F e} \mathbf{e}^{\mathbf{I I I}}(\mathbf{H b i p})$ is also not responsible. Computational studies and analogies with related electron ptransfer and spin equilibria indicate that the primary contribution is from vibrational entropy. Many low-frequency vibrational modes shift to higher energy upon oxidation of $\mathrm{Fe}^{\mathrm{II}}$ to $\mathrm{Fe} \mathrm{III}^{\mathrm{III}}$. A similar $\Delta S^{\circ}$ is also observed for the $\mathbf{F e}^{\mathrm{III}}\left(\mathbf{H}_{2} \mathbf{b i m}\right) /$ $\mathbf{F e}^{\mathbf{I I}}\left(\mathbf{H}_{2} \mathbf{b i m}\right)$ electron transfer half reaction, based on its reaction with $\mathrm{CpCp} * \mathrm{Fe}$.

The $\Delta S^{\circ}=-30 \pm 2 \mathrm{cal} \mathrm{K}^{-1} \mathrm{mo}^{-1}$ is a substantial value, corresponding to $\mathrm{T} \Delta S^{\circ}=-9 \mathrm{kcal}$ $\mathrm{mol}^{-1}$ at $298 \mathrm{~K}$ (a change in $K_{\mathrm{eq}}$ of $4 \times 10^{6}$ ). This large entropy change contradicts the common assumptions that $\Delta S^{\circ} \approx 0$ for HAT reactions, and that for a half reaction $\mathrm{AH} \rightarrow \mathrm{A}^{\bullet}+\mathrm{H}^{\bullet}, \Delta S^{\circ}$ $(\mathrm{AH}) \approx \Delta S^{\circ}\left(\mathrm{A}^{\bullet}\right)$. While the generality of this result is currently being explored, we conclude that analyses which use these entropy assumptions should be applied with care when metal complexes are involved. This includes the derivation of bond dissociation enthalpies (BDEs) from $\mathrm{p} K_{\mathrm{a}}$ and $E_{1 / 2}$ measurements via the 'Bordwell method' and the correlation of rates with BDE. In both cases, it is more appropriate to use bond dissociation free energies (BDFE) rather than enthalpies.

\section{Experimental Section}

\section{General Considerations}

All manipulations were carried out under anaerobic conditions using standard high-vacuum line and nitrogen-filled glovebox techniques unless otherwise noted. NMR spectra were acquired on Bruker Avance-500, DRX-499, Avance-300, or Avance-301 spectrometers. Static UV-Visible spectra were obtained using a Hewlett-Packard 5483 spectrophotometer equipped with an eight-cell holder thermostated with a Thermo-Neslab RTE-740 waterbath. Spectra are reported as $\lambda_{\max }, \mathrm{nm}\left[\varepsilon, \mathrm{M}^{-1} \mathrm{~cm}^{-1}\right]$. Air-sensitive samples were prepared in the glovebox and their spectra taken using either quartz cuvettes attached to Teflon-stoppered valves (Kontes) or injectable screw-capped cuvettes with silicone/PFTE septa (Spectrocell). Septa were replaced after each experiment. Rapid kinetic measurements were taken using an OLIS USA stopped-flow instrument equipped with the OLIS-rapid scanning monochromator and UV-Vis detector and thermostated by a Neslab RTE-111 waterbath.

\section{Materials}

Low water content $\mathrm{CH}_{3} \mathrm{CN}$ ( $<10 \mathrm{ppm} \mathrm{H}_{2} \mathrm{O}$; Allied Signal/Burdick and Jackson brand was taken from a keg sparged with argon and dispensed through the glovebox. Deuterated solvents (Cambridge Isotopes Laboratories) were dried and stored in the glovebox. $\mathrm{CD}_{3} \mathrm{CN}$ was dried by stirring overnight with $\mathrm{CaH}_{2}$, vacuum transferring and stirring briefly $\left(<1 \mathrm{hr}\right.$ ) over $\mathrm{P}_{2} \mathrm{O}_{5}$, vacuum transferring back over $\mathrm{CaH}_{2}$ for ca. $30 \mathrm{~min}$ and then storing free of drying agent. Acetone was dried by stirring over $\mathrm{CaSO}_{4} \cdot \mathrm{CH}_{2} \mathrm{Cl}_{2}$ was dried over $\mathrm{CaH}_{2}$ before use and stored in the glovebox freezer wrapped in $\mathrm{Al}$ foil. Other solvents were dried using a "Grubbs-type" Seca Solvent System installed by GlassContour. 65 2,2,6,6-Tetramethyl-1-piperidinyloxy (TEMPO; Acros Organics and Aldrich) was sublimed at room temperature under static vacuum before use. ${ }^{n} \mathrm{Bu}_{4} \mathrm{NClO}_{4}(99 \%$ Acros) was recrystallized twice from boiling absolute EtOH and dried overnight under dynamic vacuum. 66 Triflic Acid (99\%) was purchased from Acros Organics and stored in the glovebox freezer. All other reagents were purchased from Aldrich and used as received. 


\section{Iron complexes}

Iron(II) tris[2,2'-bi-1,4,5,6-tetrahydropyrimidine][perchlorate] $\left(\left[\mathrm{Fe}^{\mathrm{II}}\left(\mathrm{H}_{2} \text { bip }\right)_{3}\right]\left[\mathrm{ClO}_{4}\right]_{2}\right.$, $\left.\mathbf{F e}^{\mathrm{II}}\left(\mathbf{H}_{2} \mathbf{b i p}\right)\right) ;\left[\mathrm{Fe}^{\mathrm{III}}\left(\mathrm{H}_{2} \text { bip }\right)_{2}(\mathrm{Hbip})\right]\left[\mathrm{ClO}_{4}\right]_{2}\left(\mathbf{F e}^{\mathrm{III}}(\mathbf{H b i p})\right) ;\left[\mathrm{Fe}^{\mathrm{III}}\left(\mathrm{H}_{2} \text { bip }\right)_{3}\right]\left[\mathrm{ClO}_{4}\right]_{3}$ $\left(\mathbf{F e}^{\mathrm{III}}\left(\mathbf{H}_{2}\right.\right.$ bip $\left.)\right)$; iron(II) tris[2,2'-bi-2-imidazoline $][$ perchlorate $]\left(\left[\mathrm{Fe}^{\mathrm{II}}\left(\mathrm{H}_{2} \mathrm{bim}_{3}\right]\left[\mathrm{ClO}_{4}\right]_{2}\right.\right.$, $\left(\mathbf{F e}^{\mathrm{II}}\left(\mathbf{H}_{2}\right.\right.$ bim $\left.)\right) ;\left[\mathrm{Fe}^{\mathrm{III}}(\mathrm{Hbim})\left(\mathrm{H}_{2} \text { bim }\right)_{2}\right]\left[\mathrm{ClO}_{4}\right]_{2}\left(\mathbf{F e}^{\mathrm{III}}(\mathbf{H b i m})\right)$; and $\left[\mathrm{Fe}^{\mathrm{III}}\left(\mathrm{H}_{2} \text { bim }\right)_{3}\right]\left[\mathrm{ClO}_{4}\right]_{3}$ $\left(\mathrm{Fe}^{\mathrm{III}}\left(\mathbf{H}_{2}\right.\right.$ bim) ) were prepared and characterized following the procedures described in Yoder et al. ${ }^{25}$ Caution: The perchlorate salts used herein are explosive and should be handled with care in small quantities only. They should not be heated when dry or subjected to friction or shock, such as scratching with a non-Teflon-coated spatula.

CpCp*Fe was prepared from $\mathrm{FeCl}_{2}$ following the procedure of Manriquez et al. ${ }^{67}$ and purified by sublimation at $40^{\circ} \mathrm{C}$ under static vacuum. UV (MeCN): 432 [120]. [CpCp*Fe] $\mathbf{P F} \mathbf{F}_{\mathbf{6}}{ }^{37}$ was quantitatively generated in $\mathrm{MeCN}$ by addition of a stoichiometric amount of $8.1 \mathrm{mM}$ [N (tolyl $\left.)_{3}\right]\left[\mathrm{PF}_{6}\right]^{5 \mathrm{e}}$ to $3.3 \mathrm{mM} \mathrm{CpCp*Fe.} \mathrm{UV} \mathrm{(MeCN):} 740$ [350], 600 [160]. ${ }^{37}$

\section{TEMPO-H}

The literature preparation of 2,2,6,6-tetramethyl-1-hydroxypiperidine (TEMPO-H) ${ }^{30}$ was modified to give better yield and purity. A solution of TEMPO $(2.0 \mathrm{~g}, 13 \mathrm{mmol})$ in $30 \mathrm{~mL}$ of 1:1 de-ionized water/acetone was sparged with $\mathrm{N}_{2}$ for $\sim 15 \mathrm{~min}$. Under flowing $\mathrm{N}_{2}$, excess $\mathrm{Na}_{2} \mathrm{~S}_{2} \mathrm{O}_{4}(3.8 \mathrm{~g}, 22 \mathrm{mmol})$ was added and the suspension was stirred until the orange color was no longer visible (ca. $10 \mathrm{~min}$ ). Acetone was then pumped off under dynamic vacuum to yield a thick white suspension. Prolonged pumping causes a reduction in yield as the TEMPO$\mathrm{H}$ also sublimes. The product was extracted from the aqueous layer with $\mathrm{Et}_{2} \mathrm{O}(5 \times 10 \mathrm{~mL})$ by PFTE cannula, maintaining an $\mathrm{N}_{2}$ atmosphere. The $\mathrm{Et}_{2} \mathrm{O}$ was then removed under dynamic vacuum. Any residual water was removed by additional dissolution and subsequent evaporation cycles in dry $\mathrm{Et}_{2} \mathrm{O}$ as needed. Purification by sublimation at room temperature to a cold finger cooled with dry ice/acetone gave $1.5 \mathrm{~g}$ white crystalline TEMPO-H (74\%). ${ }^{1} \mathrm{H}$ NMR $\left(\mathrm{CD}_{3} \mathrm{CN}\right): \delta 1.06(\mathrm{~s}, 12 \mathrm{H}) ; \delta 1.45(\mathrm{~s}, 6 \mathrm{H}) ; \delta 5.3(\mathrm{br} \mathrm{s}, 1 \mathrm{H})$.

\section{Crystal Structures}

Detailed structural information is available in the supporting information.

\section{UV-Vis stopped-flow kinetics}

In the glovebox, a $0.1 \mathrm{mM} \mathrm{Fe}^{\mathbf{I I}}\left(\mathbf{H}_{2}\right.$ bip) solution and 4-5 solutions of TEMPO (3-80 mM, to ensure pseudo-first order conditions) were prepared in $\mathrm{CH}_{3} \mathrm{CN}$ and loaded into syringes. These were removed from the glovebox in pairs and immediately attached to the stopped-flow to minimize exposure to air. The system was thermally equilibrated for 15-25 min before data acquisition. A minimum of six kinetic runs were done at each TEMPO concentration and temperature. Typical spectra and kinetic fit are shown in Figure S2. Kinetic data were analyzed using the OLIS SVD global fitting software, averaging the $\geq 6 k_{\text {obs }}$ determinations for each temperature and concentration. The linear regressions of $k_{\mathrm{obs}}$ vs. [TEMPO] (Figure S1), and the Eyring and van't Hoff plots were done in Kaleidagraph ${ }^{\mathrm{TM}}$, weighting each rate constant with its associated standard deviation. Reported errors are double the fully propagated standard deviations. The reactions Fe $\mathbf{F}^{\mathbf{I I}}$ (Hbip) $(0.1 \mathrm{mM})+$ TEMPO-H (3-50 mM), and $\mathbf{F e}^{\mathbf{I I I}}(\mathbf{H b i m})$ $\left(2.1 \times 10^{-5} \mathrm{M}\right)+$ TEMPO-H (16-520 equiv) were measured in the same fashion (Figures S4, $\mathrm{S} 5)$. Solutions with high concentrations of TEMPO-H gradually formed tetramethylpiperidine which slowed the kinetics, so only freshly made solutions were used.

$\mathbf{F e}^{\mathrm{II}}\left(\mathbf{H}_{2}\right.$ bim $)+$ TEMPO kinetics were run under second-order approach to equilibrium conditions with a large excess of TEMPO. This was necessary because of the substantially unfavorable $K_{\text {eq }}$. Measurements followed the procedure above, using $60-80 \mu \mathrm{M}$ solutions of 
$\mathbf{F e}^{\mathrm{II}}\left(\mathbf{H}_{2} \mathbf{b i m}\right)$ and five TEMPO stock solutions $(80-500 \mathrm{mM})$. Using SPECFIT ${ }^{\mathrm{TM}}$ global analysis software ${ }^{34}$, the data were fit to a reversible second-order kinetic model with rate constants $k_{6}$ and $k_{-6}$. $\mathrm{Fe}^{\mathrm{II}}, \mathrm{Fe}^{\mathrm{III}}$ and TEMPO were defined as colored and $\mathrm{Fe}^{\mathrm{II}}$ and TEMPO had non-zero initial concentrations. Both the TEMPO spectrum and the values of $\mathrm{k}_{-6}$ (from above) were fixed in this fitting procedure, and the rate constant $k_{6}$ was iteratively refined. The extracted are independent $k_{6}$ pof [TEMPO] concentration (Figures S6, S7). The average was taken over all concentrations and the reported errors are twice the standard deviation of the set.

\section{Static Equilibria Measurements}

For each of the cases below, the relevant extinction coefficients were determined as a function of temperature and solvent using Beer's Law plots on multiple independent samples. (Table S4).

\section{$\mathrm{Fe}^{\prime \prime}\left(\mathrm{H}_{2}\right.$ bip $)+$ TEMPO $\leftrightarrows \mathrm{Fe}^{\text {III }}(\mathrm{Hbip})+$ TEMPO-H}

Individual stock solutions of 50-200 $\mu \mathrm{M} \mathrm{Fe}^{\mathbf{I I}}\left(\mathbf{H}_{2}\right.$ bip), $\sim 240 \mathrm{mM}$ TEMPO, and $\sim 160 \mathrm{mM}$ TEMPO-H were prepared in the glovebox. A UV-Vis cuvette sealed with a septum was charged with $2.0 \mathrm{~mL}$ of $\mathbf{F e}^{\mathbf{I I}}\left(\mathbf{H}_{2} \mathbf{b i p}\right)$ stock solution and thermally equilibrated in the spectrophotometer for $20 \mathrm{~min}$. A large excess of TEMPO (ca. 130 equiv) and then a series of aliquots of TEMPO$\mathrm{H}$ (up to 500 equiv) were sequentially added through the septum by syringe, with a spectrum taken after each addition, Figure S3. The additions were done as quickly as possible and various control experiments showed no measurable air-oxidation of $\mathbf{F e}^{\mathrm{II}}\left(\mathbf{H}_{2} \mathbf{b i p}\right)$ to $\mathbf{F e}^{\mathrm{III}}(\mathbf{H b i p}){ }^{26}$ Each spectrum was deconvoluted into the component absorbances of $\mathbf{F e} \mathbf{e}^{\mathbf{I I I}}(\mathbf{H b i p})$, $\mathbf{F e}^{\mathbf{I I}}\left(\mathbf{H}_{2} \mathbf{b i p}\right)$, and TEMPO (TEMPO-H has no significant absorbance in the relevant UV-Vis region) using a matrix application of Beer's Law in Microsoft Excel ${ }^{\mathrm{TM}} .68$ The resulting $p K_{\mathrm{eq}} \mathrm{S}$ were then averaged to give a single value for each cuvette (Table S1), with multiple cuvettes measured at each temperature.

\section{$\mathrm{Fe}^{\prime \prime}\left(\mathrm{H}_{2} \mathrm{bim}\right)+\mathrm{TEMPO} \leftrightarrows \mathrm{Fe}^{\mathrm{III}}(\mathrm{Hbim})+\mathrm{TEMPO}-\mathrm{H}$}

Following the method above, up to 0.13 equiv $\mathbf{F e}^{\mathbf{I I}}\left(\mathbf{H}_{2}\right.$ bim) (using a $20 \mathrm{mM}$ stock solution) was added in $50 \mu \mathrm{L}$ increments to a thermally equilibrated cuvette containing $2 \mathrm{~mL}$ of $30 \mathrm{mM}$ TEMPO in MeCN. In this approach, the change in absorbance at $676 \mathrm{~nm}$ is due solely to $\mathbf{F e}^{\text {III }}($ Hbim), rather than the strongly absorbing TEMPO background. The data analysis converted this $\Delta A_{676}$ to $\left[\mathbf{F e}^{\mathbf{I I I}}(\mathbf{H b i m})\right]$, from which the other equilibrium concentrations were derived by mass balance. Plots of $\left[\mathbf{F e}^{\mathbf{I I I}}(\mathbf{H b i m})\right]^{2}$ versus $\left[\mathbf{F e}^{\mathbf{I I}}\left(\mathbf{H}_{2} \mathbf{b i m}\right)\right]$ are linear (Figure S11, S12) with the slope being $K_{\mathrm{eq}} \times$ [TEMPO] ([TEMPO] is essentially constant under these conditions).

\section{$\mathrm{Fe}^{\text {III }}\left(\mathrm{H}_{2} \mathrm{bim}\right)+\mathrm{CpCp}{ }^{\star} \mathrm{Fe} \leftrightarrows \mathrm{Fe}^{\prime \prime}\left(\mathrm{H}_{2} \mathrm{bim}\right)+\left[\mathrm{CpCp}{ }^{\star} \mathrm{Fe}\right]^{+}$}

Again following the method above, a septum sealed cuvette was charged with $0.07 \mathrm{~g}(0.2 \mathrm{mmol})$

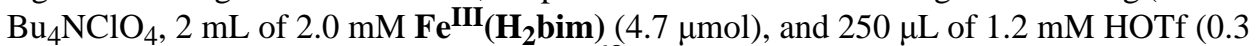
$\mu \mathrm{mol}$; added to remove trace $\mathbf{F e}^{\mathrm{III}}(\mathbf{H b i m})^{69}$ ). Once the cuvette was thermally equilibrated, aliquots of $7.4 \mathrm{mM} \mathrm{CpCp} * \mathrm{Fe}\left(0-0.31\right.$ equiv) were added and the formation of $\mathrm{CpCp} * \mathrm{Fe}^{+}$at $740 \mathrm{~nm}$ was observed. Addition of $\mathbf{F e}^{\mathbf{I I}}\left(\mathbf{H}_{2} \mathbf{b i m}\right)(1.1 \mu \mathrm{mol}, 0.23$ equiv $)$ shifted the equilibrium back towards $\mathrm{CpCp} * \mathrm{Fe}$. Data analysis was the same as for $\mathbf{F e}^{\mathbf{I I}}\left(\mathbf{H}_{2} \mathbf{b i m}\right)+$ TEMPO using the absorbance at $740 \mathrm{~nm}$ due to $[\mathrm{CpCp} * \mathrm{Fe}]^{+}$, Figure S10.

\section{Supplementary Material}

Refer to Web version on PubMed Central for supplementary material. 


\section{Acknowledgements}

We gratefully acknowledge financial support from the U.S. National Institutes of Health (grant GM50422) and from the Natural Science and Engineering Research Council of Canada (NSERC PGS D2). The authors are also indebted to Dr. A. G. DiPasquale for the X-ray crystal structures, to Drs. J. P. Roth, J. C. Yoder, and T. J. Won for their prior studies on these systems, and to others (too many to name) for valuable discussions.

\section{References}

1. (a)KochiJKFree RadicalsWileyNew York1973especially Ingold KU. Chapter 2 1:67.RussellGAChapter 71275331; and O’Neal H, Benson SW. Chapter 17 2:275-359.(b) FischerHRadical Reaction Rates in Liquids. Landolt-Börnstein New SeriesSpringerVerlagBerlini1984Volume 13, subvol. a-e1994;Volume 18, subvol. A-E(ii) (c) Hendry DG, Mill T, Piszkiewicz L, Howard JA, Eigenmann HK. J Phys Chem Ref Data 1974;3:937-978.(d) FosseyJLefortDSorbaJFree Radicals in Organic ChemistryWileyNew York1995(e)LefflerJEAn Introduction to Free RadicalsWileyNew York1993Chapters 7-8(f)HalliwellBGutteridgeJMCFree Radicals in Biology and MedicineOxford University PressNew York1999(g)SiesHOxidative Stress: Oxidants and AntioxidantsAcademicNew York, NY1991(h) FooteCSValentineJSLiebmanJGreenbergAActive Oxygen in ChemistryBlackie, Chapman and HallGlasgow 1995

2. (a) Mayer JM. Annu Rev Phys Chem 2004;55:363-390. [PubMed: 15117257] (b) Mayer JM, Rhile IJ. Biochim Biophys Acta 2004;1655:51-58. [PubMed: 15100016] (c) Mayer JM, Rhile IJ, Larsen FB, Mader EA, Markle TF, DiPasquale AG. Photosynth Res 2006;87(1):3-20. 21-24. [PubMed: 16437185] (d) Mayer JM, Mader EA, Roth JP, Bryant JR, Matsuo T, Dehestani A, Bales BC, Watson EJ, Osako T, Valliant-Saunders K, Lam W-H, Hrovat DA, Borden WT, Davidson ER. J Mol Catal A 2006;251:24-33.

3. (a) Cukier RI, Nocera DG. Annu Rev Phys Chem 1998;49:337-369. [PubMed: 9933908] (b) Stubbe J, Nocera DG, Yee CS, Chang MCY. Chem Rev 2003;103:2167-2201. [PubMed: 12797828] (c) Meyer TJ, Huynh MHV. Inorg Chem 2003;42:8140-8160. [PubMed: 14658865] (d) Lebeau EL, Binstead RA, Meyer TJ. J Am Chem Soc 2001;123:10535-10544. [PubMed: 11673985]

4. (a) Hammes-Schiffer S. Acc Chem Res 2001;34:273-281. [PubMed: 11308301] (b) Cukier RI. J Phys Chem B 2002;106:1746-1757. (c) Kuznetsov AM, Ulstrup J. Can J Chem 1999;77:1085-1096. (d) Krishtalik LI. Biochim Biophys Acta 2000;1458:6-27. [PubMed: 10812022] (e) Hatcher E, Soudackov A, Hammes-Schiffer S. Chem Phys 2005;319:93-100. (f) Cukier RI. ACS Symp Series 2004;883:145-158.(Molecular Bioenergetics)

5. (a) Biczók L, Gupta N, Linschitz H. J Am Chem Soc 1997;119:12601-12609. (b) Sjödin M, Ghanem R, Polivka T, Pan J, Styring S, Sun L, Sundström V, Hammarström L. Phys Chem Chem Phys 2004;6:4851-4858. (c) Reece SY, Nocera DG. J Am Chem Soc 2005;127:9448-9458. [PubMed: 15984872] (d) Costentin C, Evans DH, Robert M, Savéant JM, Singh PS. J Am Chem Soc 2005;127:12490-12491. [PubMed: 16144387] (e) Rhile IJ, Markle TF, Nagao H, DiPasquale AG, Lam OP, Lockwood MA, Rotter K, Mayer JM. J Am Chem Soc 2006;128:6075-6088. [PubMed: 16669677] (f) Fecenko CJ, Meyer TJ, Thorp HH. J Am Chem Soc 2006;128:11020-11021. [PubMed: 16925408]

6. (a) Mayer JM, Hrovat D, Thomas JL, Borden WT. J Am Chem Soc 2002;124:11142-11147. [PubMed: 12224962] (b) Lingwood M, Hammond JR, Hrovat DA, Mayer JM, Borden WT. J Chem Theory Comput 2006;2:740-745. [PubMed: 18725967] (c) Pratt DA, Blake JA, Mulder P, Walton JC, Korth HG, Ingold KU. J Am Chem Soc 2004;126:10667-10675. [PubMed: 15327325]

7. (a) Stubbe J, van der Donk WA. Chem Rev 1998;98:705-762. [PubMed: 11848913] (b) Pesavento RP, van der Donk WA. Adv Protein Chem 2001;58:317-385. [PubMed: 11665491] (c) Marsh ENG. BioEssays 1995;17:431-441. [PubMed: 7786289] (d) Pierre JL, Thomas F. Compt Rend Chim 2005;8:65-74. (e) Fontecave M, Pierre JL. Comptes Rendus Acad Sci Ser II C 2001;4:531-538. (f) Decker A, Chow MS, Kemsley JN, Lehnert N, Solomon EI. J Am Chem Soc 2006;128:4719-4733. [PubMed: 16594709]

8. (a) Labinger JA. J Mol Catal A 2004;220:27-35. (b) Labinger JA. Catal Lett 1988;1:371-375.

9. (a) Liang ZX, Klinman JP. Curr Opin Struct Bio 2004;14:648-655. [PubMed: 15582387] (b) Hatcher E, Soudackov AV, Hammes-Schiffer S. J Am Chem Soc 2004;126:5763-5775. [PubMed: 15125669] 
(c) Lehnert N, Solomon EI. J Biol Inorg Chem 2003;8:294-305. [PubMed: 12589565] (d) Goldsmith CR, Stack TDP. Inorg Chem 2006;45:6048-6055. [PubMed: 16842013]

10. (a) Ragsdale SW. Chem Rev 2006;106:3317-3337. [PubMed: 16895330] (b) Baik MH, Newcomb M, Friesner RA, Lippard SJ. Chem Rev 2003;103:2385-2419. [PubMed: 12797835] (c) Brazeau BJ, Austin RN, Tarr C, Groves JT, Lipscomb JD. J Am Chem Soc 2001;123:11831-11837. [PubMed: 11724588]

11. (a)ShaikSSSchlegelHBWolfeSTheoretical Aspects of Physical Organic Chemistry: The $\mathrm{S}_{\mathrm{N}} 2$ ReactionJohn Wiley \& Sons, Inc.New York19921123(b)KnoxJHRate Constants in the Gas-Phase Oxidation of Alkanes and Alkyl RadicalsMayoFROxidation of Organic Compounds. Adv Chem Ser196876II122(c)References 1a,d,e

12. Eq (2) is not limited to standard states, so $\Delta H$ rather than $\Delta H^{\circ}$ is used. Bond dissociation energies are $\Delta H^{\circ}$ values and are defined at $298 \mathrm{~K}$ and 1 atmosphere (gas-phase BDEs) or unit activity standard state ([assumed $1 \mathrm{M}$ ] for solution BDEs).

13. Mayer JM. Acc Chem Res 1998;31:441-450.

14. Roth JP, Yoder JC, Won TJ, Mayer JM. Science 2001;294:2524-2526. [PubMed: 11752572]

15. (a) Albery WJ. Ann Rev Phys Chem 1980;31:227-263. (b) Kristjánsdóttir SS, Norton JR. J Am Chem Soc 1991;113:4366-4367. (c) Guthrie JP. J Am Chem Soc 1997;119:1151-1152. (d) Lee ISH, Jeoung EH, Kreevoy MM. J Am Chem Soc 1997;119:2722-2728. and references therein. (e) Lewis ES, Hu DD. J Am Chem Soc 1984;106:3292-3296. (f) Pellerite MJ, Brauman JI. J Am Chem Soc 1983;105:2672-2680. (f) Shea TM, Deraniyagala SP, Studebaker DB, Westmoreland TD. Inorg Chem 1996;35:7699-7703. (g) Anderson KA, Kirchner K, Dodgen HW, Hunt JP, Wherland S. Inorg Chem 1992;31:2605-2608.(h) Reference 11a.

16. Mader EA, Larsen AS, Mayer JM. J Am Chem Soc 2004;126:8066-8067. [PubMed: 15225018]

17. (a) Marcus RA, Sutin N. Biochim Biophys Acta 1985;811:265-322. (b) Sutin N. Prog Inorg Chem 1983;30:441.

18. Blanksby SJ, Ellison GB. Acc Chem Res 2003;36:255-263. [PubMed: 12693923]

19. (a) Wiberg KB, Foster G. J Am Chem Soc 1961;83:423-429.(thermochemical cycle is on p. 425) (b) Eberson L. Acta Chem Scand 1963;17:2004-2018. (c) Jaun B, Schwarz J, Breslow R. J Am Chem Soc 1980;102:5741-5748. and references therein

20. Leading references: (a) Bordwell FG, Cheng JP, Ji GZ, Satish AV, Zhang X. J Am Chem Soc 1991;113:9790-9795. (b) Bordwell FG, Cheng JP, Harrelson JA Jr. J Am Chem Soc 1988;110:1229_ 1231. (c) Bordwell FG, Satish AV, Zhang S, Zhang XM. Pure \& Appl Chem 1995;67(5):735-740. (d) Bordwell FG, Liu WZ. J Am Chem Soc 1996;118:10819-10823.

21. A subset of the references in this area are: (a) Anne A, Fraoua S, Grass V, Moiroux J, Savéant JM. J Am Chem Soc 1998;120:2951-2958. (b) Koshino N, Cai Y, Espenson JH. J Phys Chem A 2003;107:4262-4267. (c) Cheng JP, Liu B, Zhao Y, Wen Z, Sun Y. J Am Chem Soc 2000;122:99879992. (d) reference 5e.

22. A subset of the references using BDE's are: (a) Parker VD, Handoo KL, Roness F, Tilset M. J Am Chem Soc 1991;113:7493-7498. (b) Tilset M, Parker VD. J Am Chem Soc 1990;112:2843. (c) Tilset M, Parker VD. J Am Chem Soc 1989;111:6711-6717. (d) Borovik AS. Acc Chem Res 2005;38:5461. [PubMed: 15654737] (e) Zhang J, Grills DC, Huang KW, Fujita E, Bullock RM. J Am Chem Soc 2005;127:15684-15685. [PubMed: 16277493] (f) Carrell TG, Bourles E, Lin M, Dismukes GC. Inorg Chem 2003;42:2849-2858. [PubMed: 12716176] (g) Astruc D. Acc Chem Res 2000;33:287298. [PubMed: 10813873] (h) Wang D, Angelici RJ. J Am Chem Soc 1996;118:935-942. (i) Eisenberg DC, Norton JR. Isr J Chem 1991;31:55-66. (j) Simões JAM, Beauchamp JL. Chem Rev 1990;90:629-688. (k) Reference 61b.

23. (a) Wayner DDM, Parker VD. Acc Chem Res 1993;26:287-294.and references therein. (b) Tang L, Papish ET, Abramo GP, Norton JR, Baik MH, Friesner RA, Rappe A. J Am Chem Soc 2003;125:10093-10102. [PubMed: 12914473] and 2006, 128, 11314

24. For a few studies using BDFE's, see: (a) Fu X, Wayland BB. J Am Chem Soc 2005; 127:1646016467. [PubMed: 16305232] and references therein. (b) Miedaner A, Raebiger JW, Curtis CJ, Miller SM, DuBois DL. Organometallics 2004;23:2670-2679. (c) Ellis WW, Miedaner A, Curtis CJ, Gibson DH, DuBois DL. J Am Chem Soc 2002;124:1926-1932. [PubMed: 11866605] 
25. Yoder JC, Roth JP, Gussenhoven EM, Larsen AS, Mayer JM. J Am Chem Soc 2003;125:2629-2640. [PubMed: 12603151]

26. (a) Burnett MG, McKee V, Nelson SM. J Chem Soc, Dalton Trans 1981:1492-1497. (b) Burnett MG, McKee V, Nelson SM. J Chem Soc, Chem Commun 1980;13:599-601. (c) Wang JC, Bauman JE Jr. Inorg Chem 1965;4:1613-1615.

27. Roth JP, Lovell S, Mayer JM. J Am Chem Soc 2000;122:5486-5498.

28. (a) van Koningsbruggen PJ, Maeda Y, Oshio H. Top Curr Chem 2004;233:259-324. (b) Gutlich P, Goodwin AH. Top Curr Chem 2004;233:1-47. (c) Konig E. Struct Bonding (Berlin) 1991;76:51152.

29. (a) Sunatsuki Y, Ohta H, Kojima M, Ikuta Y, Goto Y, Matsumoto N, Iijima S, Akashi H, Kaizaki S, Dahan F, Tuchagues JP. Inorg Chem 2004;43:4154-4171. [PubMed: 15236527] (b) Maroney MJ, Fey EO, Baldwin DA, Stenkamp RE, Jensen LH, Rose NJ. Inorg Chem 1986;25:1409-1414. (c) Saha NC, Butcher RJ, Chaudhuri S, Saha N. Polyhedron 2003;22:375-381. (d) Endicott JF, Durham B, Glick MD, Anderson TJ, Kuszaj JM, Schmonsees WG, Balakrishnan KP. J Am Chem Soc 1981;103:1431-1440.

30. Ozinskas AJ, Bobst AM. Helv Chim Acta 1980;63:1407-1411.

31. Capiomont PA, Lajzerowicz-Bonneteau J. Acta Cryst B 1974;30:2160-2166.

32. Matheson, IBC. RSM-1000 Global Fit Software version 63. On-Line Instrument Systems (Olis), Inc.; 1998.

33. Roth, JP. Intrinsic and Thermodynamic Influences on Hydrogen Atom Transfer Reactions Involving Transition Metal Complexes. Ph.D., University of Washington; Seattle, WA: 2000.

34. SPECFIT/32, versions v3.0.26 and v3.0.36; Spectrum Software Associates, 2000.

35. Espenson, JH. Chemical Kinetics and Reaction Mechanisms. 2. McGraw-Hill, Inc.; New York: 1995. p. 70-95.p. 158

36. The solvatochromism for TEMPO is negligible in our measurements in $\mathrm{MeCN}, \mathrm{CH}_{2} \mathrm{Cl}_{2}$, and acetone, but is significant in a wider range of solvents: Glowacka J, Szczepek WJ, Wrona PK. Polish J Chem 2000;74:1341-1348.

37. Our measurements of the $[\mathrm{CpCp} * \mathrm{Fe}]^{+} \lambda_{\max }$ and $\varepsilon$ are close to previous reports: (a) Nelsen SF, Chen LJ, Ramm MT, Voy GT, Powell DR, Accola MA, Seehafer TR, Sabelko JJ, Pladziewicz JR. J Org Chem 1996;61:1405-1412. (b) Nelsen SF, Wang Y, Ramm MT, Accola MA, Pladziewicz JR. J Phys Chem 1992;96:10654-10658. (c) Duggan DM, Hendrickson DN. Inorg Chem 1975;14:955-970.

38. Noviandri I, Brown KN, Fleming DS, Gulyas PT, Lay PA, Masters AF, Phillips L. J Phys Chem B 1999;103:6713-6722.

39. All potentials are referenced in $\mathrm{MeCN}$ with $0.1 \mathrm{M} \mathrm{NBu}_{4} \mathrm{ClO}_{4}$ vs. ferrocene

40. Yee EL, Cave RJ, Guyer KL, Tyma PD, Weaver MJ. J Am Chem Soc 1979;101:1131-1137.

41. For system with spin $\mathrm{S}$, the number of states $\mathrm{W}=2 \mathrm{~S}+1$ and the spin entropy $S^{\circ}=\mathrm{R} \ln (W)$. For a spin change from $3 / 2$ to $5 / 2, S^{\circ}=R \ln (2[5 / 2]+1)-R \ln \left(2\left[\frac{3}{2}\right]+1\right)=0.8 \mathrm{cal} \mathrm{mol}^{-1} \mathrm{~K}^{-1}$.

42. NIST Chemistry WebBook, NIST Standard Reference Database Number 69 - March, 2003 Release, http://webbook.nist.gov/chemistry/

43. Burcat, A.; Ruscic, B. TAE Report No. 960, Technion, Haifa. 2005. see also ftp://ftp.technion.ac.il/pub/supported/aetdd/thermodynamics

44. Ruscic B, Boggs JE, Burcat A, Császár AG, Demaison J, Janoschek R, Martin JML, Morton ML, Rossi MJ, Stanton JF, Szalay PG, Westmoreland PR, Zabel F, Bérces T. J Phys Chem Ref Data 2005;34(2):573-656.

45. Curran H, Wu C, Marinov N, Pitz WJ, Westbrook CK, Burcat A. J Phys Chem Ref Data 2000;29:463517.

46. Lucarini M, Pedulli GF, Cipollone M. J Org Chem 1994;59:5063-5070.

47. Lucarini M, Pedrielli P, Pedulli GF, Valgimigli D, Gigmes D, Tordo P. J Am Chem Soc 1999;121:11546-11553.

48. Ref. $23 \mathrm{a}$ actually finds that $\Delta H^{\mathrm{o}}$ solvation $\left[\mathrm{AH}-\mathrm{A}^{\bullet}\right]+\mathrm{T} \Delta S^{\mathrm{o}}{ }_{13}\left[\mathrm{AH}-\mathrm{A}^{\bullet}\right] \approx-2.2 \mathrm{kcal} \mathrm{mol}^{-1}$ in $\mathrm{MeCN}$, which the authors contribute mostly to $\Delta H^{\circ}$ solvation $\left[\mathrm{AH}-\mathrm{A}^{\bullet}\right]$. 
49. (a) Snelgrove DW, Lusztyk J, Banks JT, Mulder P, Ingold KU. J Am Chem Soc 2001;123:469-477. (b) Litwinienko G, Ingold KU. J Org Chem 2005;70:8982-8990. [PubMed: 16238337] (c) Litwinienko G, Ingold KU. J Org Chem 2004;69:5888-5896. [PubMed: 15373474]

50. Avila DV, Brown CE, Ingold KU, Lusztyk J. J Am Chem Soc 1993;115:466-470.

51. Riddick, JA.; Bunger, WB. Organic Solvents: Physical Properties and Methods of Purification. 3. Weissberger, A., editor. 2. Techniques of Chemistry; Wiley-Interscience; New York: 1970. p. 243p. 349p. 400

52. (a) Abraham MH, Platts JA. J Org Chem 2001;66:3484-3491. [PubMed: 11348133] (b) Abraham MH, Grellier PL, Prior DV, Taft RW, Morris JJ, Taylor PJ, Laurence C, Berthelot M, Doherty RM, Kamlet MJ, Abboud JLM, Sraidi K, Guiheneuf G. J Am Chem Soc 1988;110:8534-8536. (c) Abraham MH, Grellier PL, Prior DV, Morris JJ, Taylor PJ. J Chem Soc, Perkin Trans 2 1990:521529. (d) Abraham MH, Grellier PL, Prior DV, Duce PP, Morris JJ, Taylor PJ. J Chem Soc, Perkin Trans 2 1989:699-711.

53. This is a factor of $1 / 15$ in equilibrium constant due to the fifteen-fold degeneracy of the ${ }^{5} \mathrm{~T}_{2 \mathrm{~g}}$ state. Any splitting of the states from lower than $O_{\mathrm{h}}$ symmetry or from spin-orbit coupling would reduce $\Delta S_{\text {elec. }}^{\text {o }}$

54. (a) Turner JW, Schultz FA. Coord Chem Rev 2001;219-221:81-97. (b) Goodwin HA. Top Curr Chem 2004;233:59-90.

55. (a) Richardson DE, Sharpe P. Inorg Chem 1993;32:1809-1812. (b) Richardson DE, Sharpe P. Inorg Chem 1991;30:1412-1414.

56. (a) Turner JW, Schultz FA. J Phys Chem B 2002;106:2009-2017. (b) Turner JW, Schultz FA. Inorg Chem 2001;40:5296-5298. [PubMed: 11559097] (c) Sharpe P, Kebarle P. J Am Chem Soc 1993;115:782-789. (d) Kratochvil B, Knoeck J. J Phys Chem 1966;70:944-946. (e) Turner JW, Schultz FA. Inorg Chem 1999;38:358-364. (f) Hupp JT, Weaver MJ. Inorg Chem 1983;22:25572564. (g) Sahami S, Weaver MJ. J Electroanal Chem Interfacial Electrochem 1981;122:155-170. (h) Sahami S, Weaver MJ. J Electroanal Chem Interfacial Electrochem 1981;122:171-181. (i) Hupp JT, Weaver MJ. Inorg Chem 1984;23:3639-3644. (j) Hupp JT, Weaver MJ. Inorg Chem 1984;23:256258. (k) Yee EL, Weaver MJ. Inorg Chem 1980;19:1077-1079.

57. (a) Sorai M, Seki S. J Phys Chem Solids 1974;35:555-570. (b) Tuchagues JP, Bousseksou A, Molnar G, McGarvey JJ, Varret F. Top Curr Chem 2004;235:85-103.

58. Sutin N, Weaver MJ, Yee EL. Inorg Chem 1980;19:1096-1098.

59. (a) Wherland S. Coord Chem Rev 1993;123:169-199.Eberson, L. Electron Transfer Reactions in Organic Chemistry. Springer-Verlag; Berlin: 1987.

60. Complications in determining gas phase energetics from cycles like Scheme 2 arise when A-H is a strong hydrogen bond donor and significant hydrogen-bonding to solvent is present. Leading references include: (a) Mulder P, Korth HG, Pratt DA, DiLabio GA, Valgimigli L, Pedulli GF, Ingold KU. J Phys Chem A 2005;109:2647-2655. [PubMed: 16833571] (b) dos Santos RMB, Simões JAM. J Phys Chem Ref Data 1998;27:707-739.

61. Excellent discussions on the derivation of $C_{\mathrm{G}}$ and $C_{\mathrm{H}}$ are provided in (a)TilsetMBalzaniVThe Thermodynamics of Organometallic Systems Involving Electron-transfer Paths. Electron Transfer in ChemistryWiley-VCHNew York20012677713(b)MayerJMMeunierBBiomimetic Oxidations Catalyzed by Transition Metal ComplexesImperial College PressLondon2000143

62. $\Delta \mathrm{S}^{\circ}\left[\mathrm{H}^{\bullet}\right]=\mathrm{S}_{\mathrm{f}}^{\circ}\left[\mathrm{H}^{\bullet}\right]_{\mathrm{g}}+\Delta \mathrm{S}^{\circ}$ solvation $\left[\mathrm{H}^{\bullet}\right]$ See supporting information for details. (a) $\mathrm{S}_{\mathrm{f}}^{\circ}\left[\mathrm{H}^{\bullet}\right]_{\mathrm{g}}=27.419$ $\mathrm{cal} \mathrm{mol}^{-1} \mathrm{~K}^{-1}$; NIST Standard Reference Database 69, June 2005 Release: NIST Chemistry WebBook. http://webbook.nist.gov/chemistry/(b) $\Delta \mathrm{S}^{\circ}$ solvation $\left[\mathrm{H}^{\circ}\right]$ is approximated by the solvation entropy of $\mathrm{H}_{2}$ in the same solvent. See Roduner E, Bartels DM. Ber Bunsen-Ges Phys Chem 1992;96:1037-1042.(c) $\Delta \mathrm{S}^{\circ}$ solvation $\left[\mathrm{H}_{2}\right]$ in $\mathrm{MeCN}$ and toluene; Brunner E. J Chem Eng Data 1985;30:269-273.(d) $\Delta \mathrm{S}^{\circ}$ solvation $\left[\mathrm{H}_{2}\right]$ in $\mathrm{H}_{2} \mathrm{O}$, DMSO, and 1,2 dichloroethane; IUPAC, Solubility Data Series. YoungCLHydrogen and DeuteriumPergamon PressNew York19811356259239

63. Both values should have been reduced by $5 \mathrm{kcal} \mathrm{mol}^{-1}$ to make them true BDFE's (eq 20). However, since $K_{\mathrm{eq}}$ requires the difference between $\mathrm{Fe}^{\mathrm{II}}\left(\mathrm{H}_{2} \mathrm{~L}\right)$ and the organic BDE, this correction cancels out, yielding the correct $K_{\mathrm{eq}}$. This would not be the case, for instance, if our measurement of the BDE for $\mathrm{Fe}^{\mathrm{II}}\left(\mathrm{H}_{2} \mathrm{~L}\right)$ had been done using calorimetry, which does not account for $S^{\circ}\left(\mathrm{Fe}^{\mathrm{II}}\left(\mathrm{H}_{2} \mathrm{~L}\right)\right)-S^{\circ}$ $\left(\mathrm{Fe}^{\mathrm{III}}(\mathrm{HL})\right)$. In this case, the resulting $\Delta \mathrm{BDE}$ would yield an $\Delta H^{\circ}$ value, not $\Delta G^{\circ}$. 
64. Lowry, TH.; Richardson, KS. Mechanism and Theory in Organic Chemistry. Chapter 2. Harper \& Row, Publishers; San Francisco: 1976.

65. Pangborn, AB.; Giardello, MA.; Grubbs, RH.; Rosen, RK.; Timmers, FJ. Organometallics. 1996. p. 1518 -1520.http://www.glasscontour.com/index.html

66. Perrin, DD.; Armarego, WLF. Purification of Laboratory Chemicals. 3. Pergamon Press; New York: 1989. p. 280

67. Manriquez JM, Bunel EE, Oelckers B. Inorg Synth 1997;31:214-217.

68. Least Squares Methods for Multivariate Data. User manual SPECFIT/32. Spectrum Software Associates; Marlbourough, MA: 2000-2001. p. 95-96.

69. Samples of $\mathrm{Fe}^{\mathrm{III}}\left(\mathrm{H}_{2}\right.$ bim) always appeared to contain trace amounts $(<1 \%)$ of $\mathrm{Fe}^{\mathrm{III}}(\mathrm{Hbim})$. Based on the UV-Vis absorbance of $\mathrm{Fe}^{\mathrm{III}}(\mathrm{Hbim})$ at $676 \mathrm{~nm}, 1$ equiv HOTf was added to fully protonate the sample to $\mathrm{Fe}^{\mathrm{III}}\left(\mathrm{H}_{2}\right.$ bim $)$. Excess HOTf resulted in decomposition of $\mathrm{Fe}^{\mathrm{III}}\left(\mathrm{H}_{2}\right.$ bim $)$. 
A

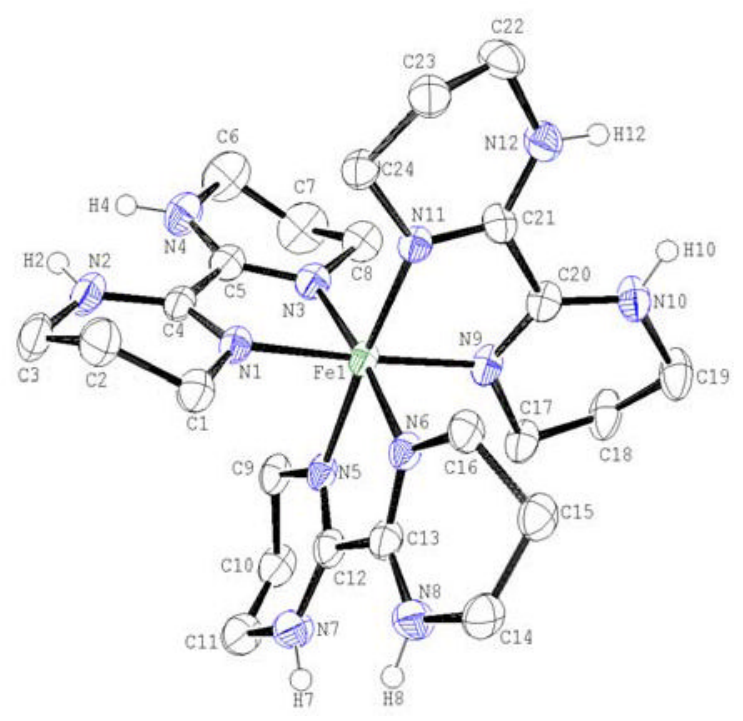

B

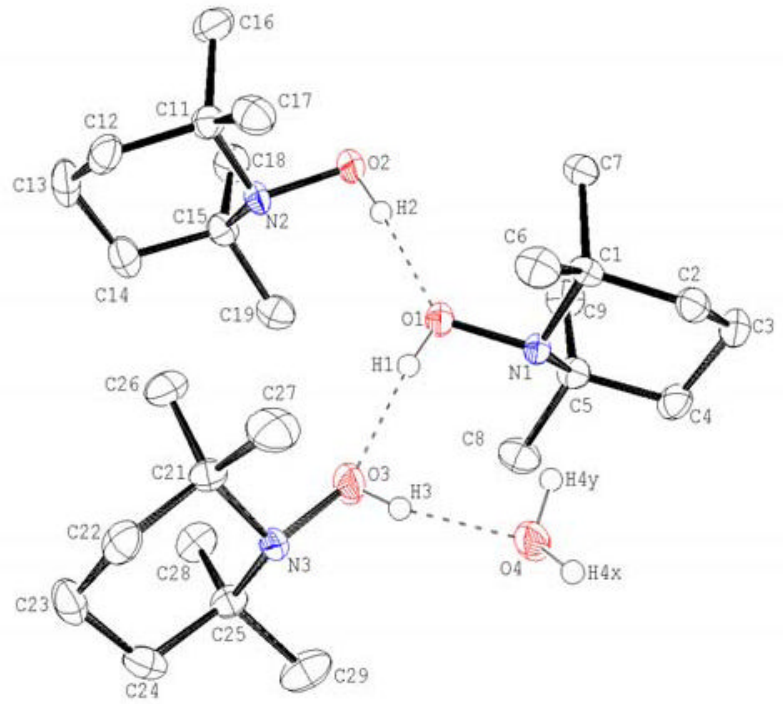

Figure 1.

ORTEPs of (A) the cation in $\mathrm{Fe}^{\mathrm{III}}\left(\mathrm{H}_{2} \text { bip }\right)_{3}\left(\mathrm{ClO}_{4}\right)_{3} \bullet \mathrm{MeCN} \bullet \mathrm{Et}_{2} \mathrm{O}$ and $(\mathrm{B})$ the unit cell of TEMPO-H॰1/3 $\mathrm{H}_{2} \mathrm{O}$. Thermal ellipsoids are drawn at $50 \%$ probability; only the hydrogen atoms bound to $\mathrm{N}$ or $\mathrm{O}$ are shown. 

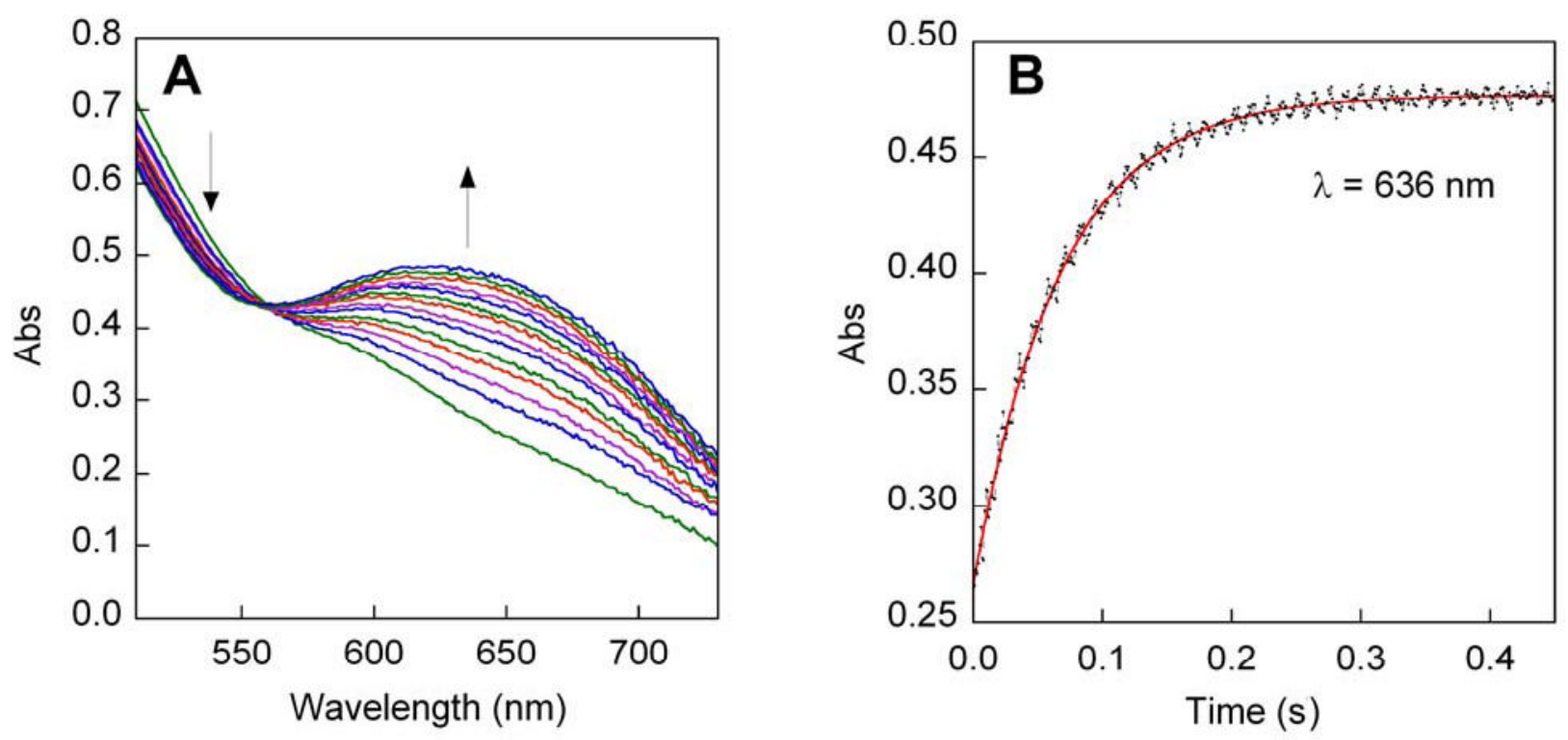

Figure 2.

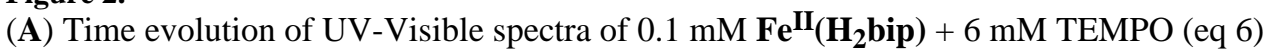
over $0.5 \mathrm{~s}$ at $298 \mathrm{~K}$ in $\mathrm{MeCN}$. (B) Match between the original data $(\bullet$ ) and the pseudo first order fit ( - ) resulting from OLIS SVD Global Analysis over the whole wavelength region in $\mathbf{A}$. Shown only for a single wavelength, $636 \mathrm{~nm}$. 


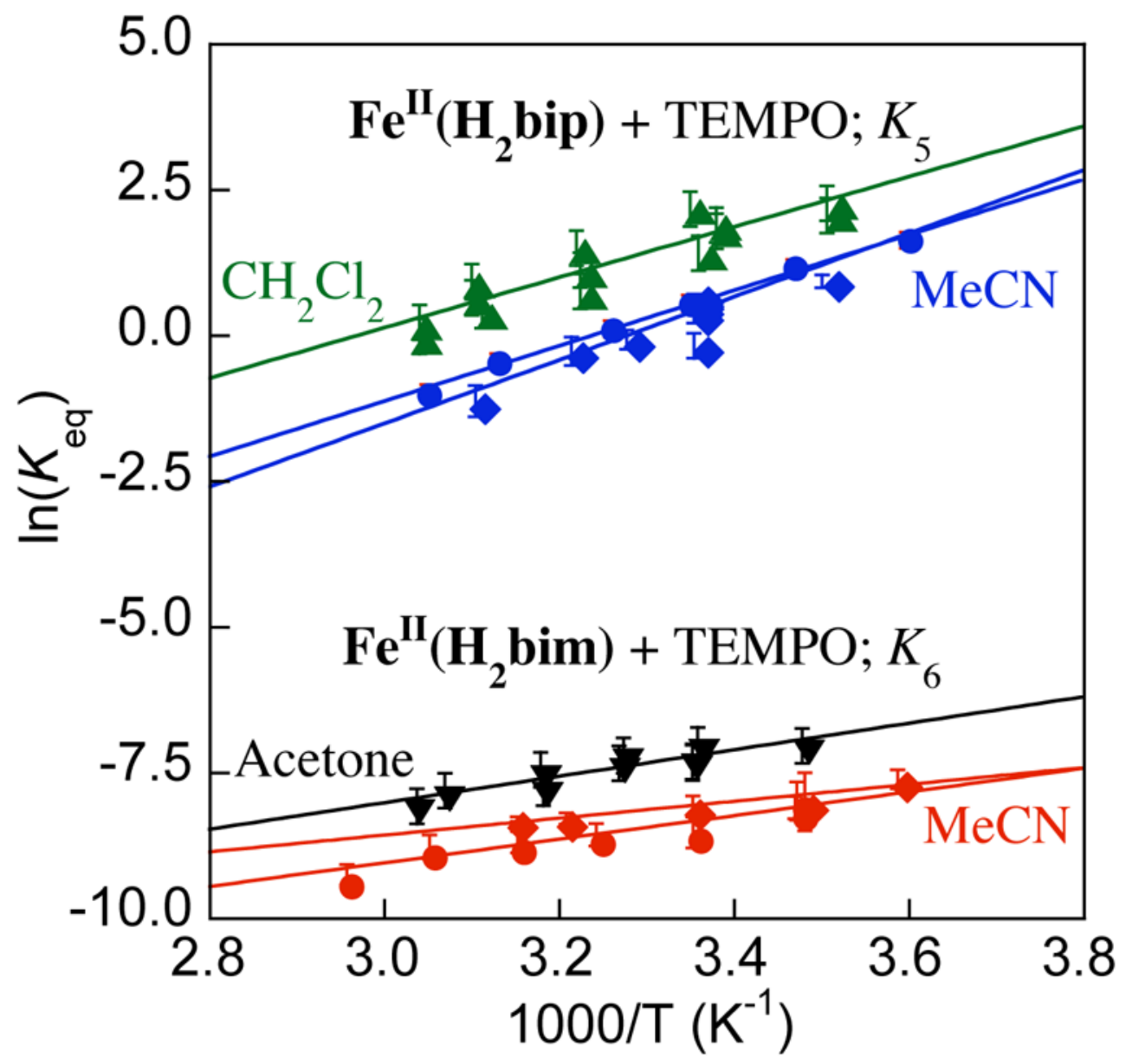

Figure 3.

Van't Hoff plots. Top: Fe $\mathbf{I I}_{\left(\mathbf{H}_{2} \mathbf{b i p}\right)}+$ TEMPO (eq 5): kinetic measurements in MeCN (blue -); static measurements in $\mathrm{MeCN}$ (blue $\diamond$ ); static measurements in $\mathrm{CH}_{2} \mathrm{Cl}_{2}$ (green $\boldsymbol{\Delta}$ ). Bottom: $\mathbf{F e}^{\mathbf{I I}}\left(\mathbf{H}_{2}\right.$ bim) + TEMPO (eq 6): kinetic measurements in $\mathrm{MeCN}$ (red $\bullet$ ); static measurements in $\mathrm{MeCN}($ red $\diamond)$; static measurements in acetone (black $\boldsymbol{\nabla}$ ). 


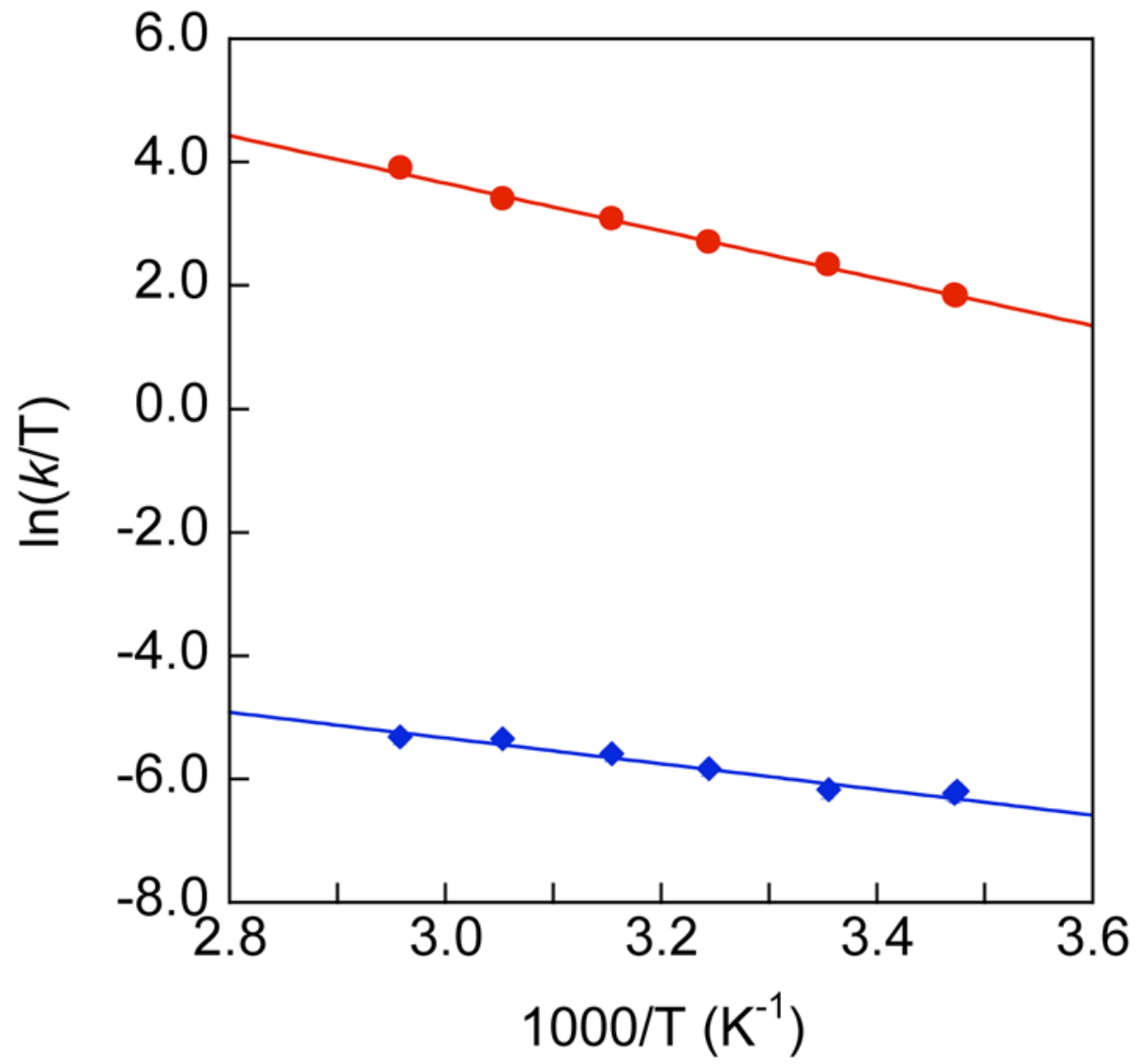

Figure 4.

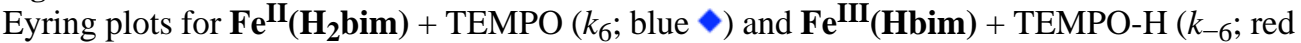
•) in $\mathrm{MeCN}$. 


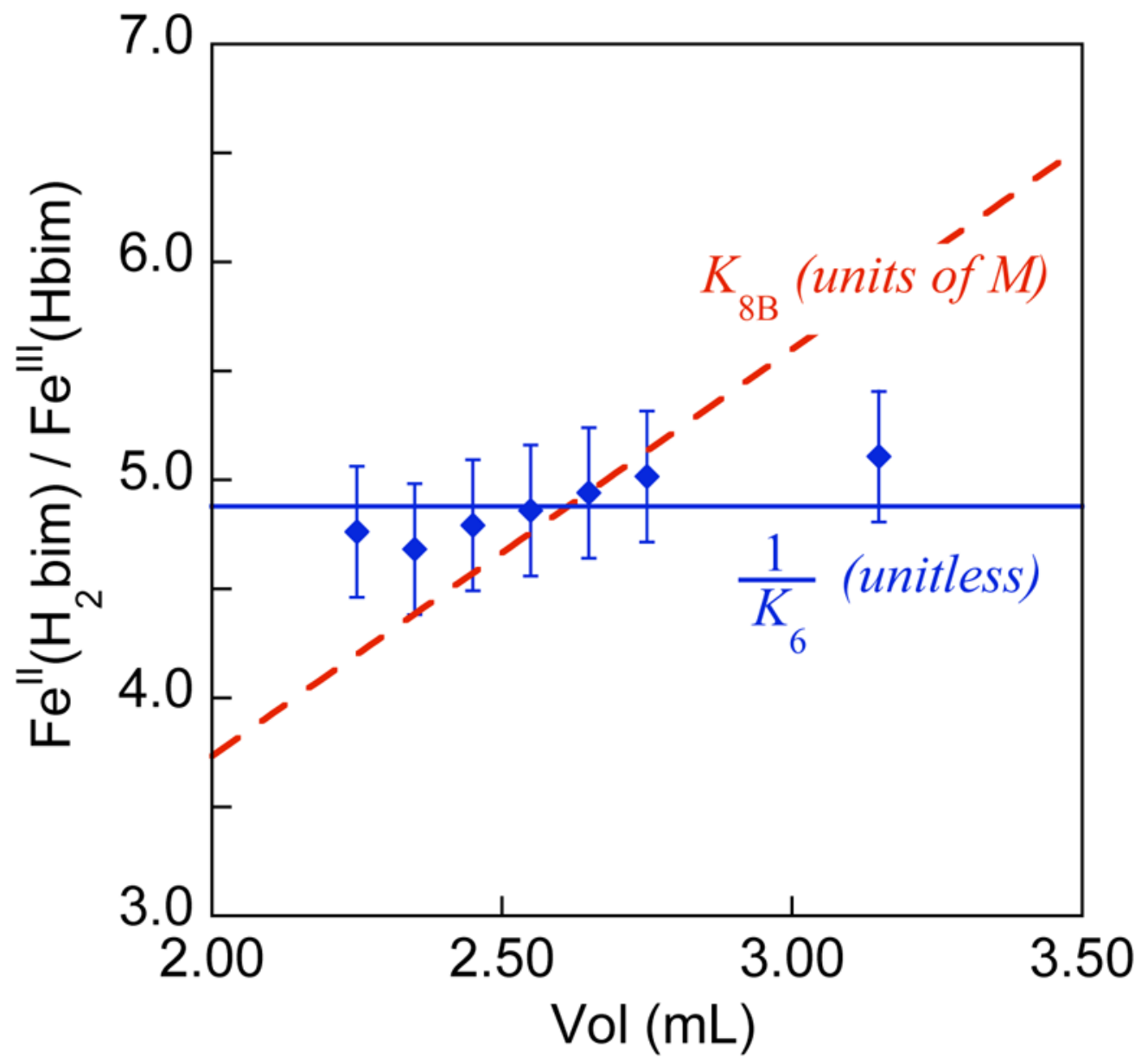

Figure 5.

Plot of $\mathbf{F e}^{\text {II }}\left(\mathbf{H}_{2}\right.$ bim $) / \mathbf{F e}^{\text {III }}(\mathbf{H b i m})$ vs. total volume upon dilution of an equilibrium mixture of $1.03 \mu \mathrm{mol} \mathbf{F e}^{\mathbf{I I}}\left(\mathbf{H}_{2} \mathbf{b i m}\right)$ and $85.5 \mu \mathrm{mol}$ TEMPO (eq 6) with MeCN. The blue horizontal line $(-)$ is the prediction for the unitless $1 / K_{6}$ (eq 7). The red dashed line (---) is the prediction for an equilibrium constant with units of $\mathrm{M}$, for instance involving a hydrogen-bonded adduct such as $K_{8 \mathrm{~B}}\left(=k_{8 \mathrm{~B}} / k_{-8 \mathrm{~B}}\right)$ in eq 8 . 

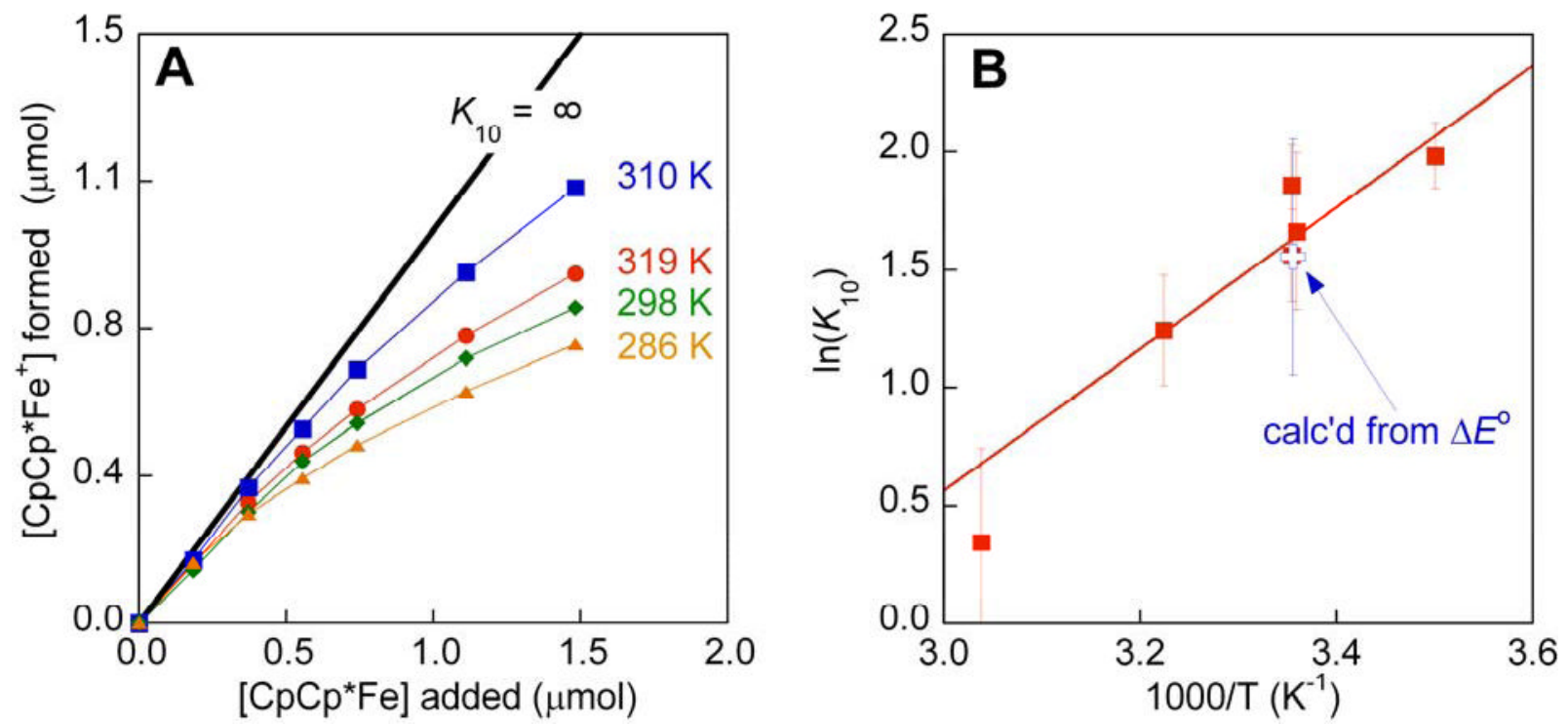

Figure 6.

$\mathbf{F e}^{\mathbf{I I}}\left(\mathbf{H}_{2} \mathbf{b i m}\right)+[\mathrm{CpCp} * \mathrm{Fe}]^{+}\left(\right.$eq 10; $\left.\mathrm{MeCN}, 0.09 \mathrm{M}^{n} \mathrm{Bu}_{4} \mathrm{NClO}_{4}\right)(\mathbf{A})$ Formation of $[\mathrm{CpCp} * \mathrm{Fe}]^{+}$as a function of added $\mathrm{CpCp} * \mathrm{Fe}$ at various temperatures. (B) van't Hoff plot. 


$$
\begin{array}{ccc}
{\left[\mathrm{Fe}^{\mathrm{II}}\left(\mathrm{H}_{2} \mathrm{bim}\right)_{3}\right]^{2+}+[\mathrm{CpCp} * \mathrm{Fe}]^{+} \longrightarrow\left[\mathrm{Fe}^{\mathrm{III}}\left(\mathrm{H}_{2} \mathrm{bim}\right)_{3}\right]^{3+}+\mathrm{CpCp}^{*} \mathrm{Fe}} & \frac{\Delta S^{0}\left(\mathrm{cal} \mathrm{mol}^{-1} \mathrm{~K}^{-1}\right)}{-17 \pm 3} \\
\mathrm{CpCp}^{*} \mathrm{Fe} \longrightarrow\left[\mathrm{CpCp}^{*} \mathrm{Fe}\right]^{+}+e^{-} & -11.7 \pm 0.5 \\
\hline\left[\mathrm{Fe}^{\mathrm{II}}\left(\mathrm{H}_{2} \mathrm{bim}\right)_{3}\right]^{2+} \longrightarrow\left[\mathrm{Fe}^{\mathrm{III}}\left(\mathrm{H}_{2} \mathrm{bim}\right)_{3}\right]^{3+}+e^{-} & -29 \pm 3
\end{array}
$$

Scheme 1.

Entropy of electron transfer: $\mathbf{F e}^{\mathbf{I I I}}\left(\mathbf{H}_{2} \mathbf{b i m}\right)+\mathrm{CpCp} * \mathrm{Fe}$. 


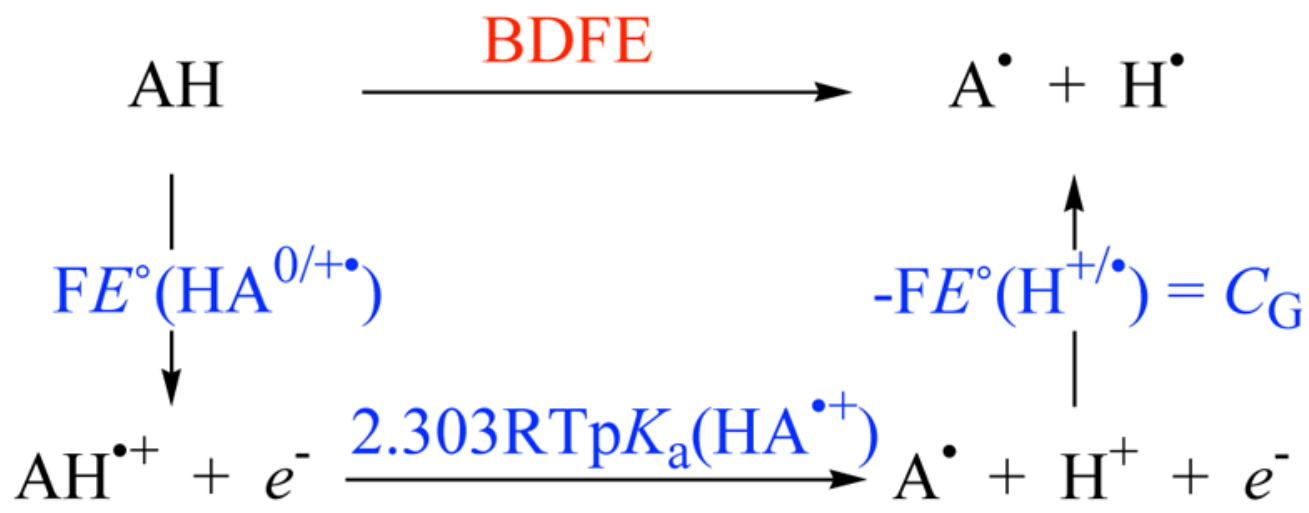

Scheme 2. 
Table 1

Selected bond length $(\AA)$ and angles (deg) for $\mathbf{F e}^{\mathrm{III}}\left(\mathbf{H}_{2} \mathbf{b i p}\right)$ and $\mathbf{F e}^{\boldsymbol{n}}\left(\mathbf{H}_{\boldsymbol{x}} \mathbf{b i m}\right)$ structures. ${ }^{a}$

\begin{tabular}{|c|c|c|c|c|}
\hline & $\mathrm{Fe}^{\mathrm{III}}\left(\mathrm{H}_{2} \mathrm{bip}\right)^{b}$ & $\mathrm{Fe}^{\mathrm{III}}\left(\mathrm{H}_{2} \mathrm{bim}\right)^{c, d}$ & $\mathrm{Fe}^{\mathrm{IIII}}(\mathrm{Hbim}){ }^{c, e}$ & $\mathrm{Fe}^{\mathrm{II}}\left(\mathrm{H}_{2} \mathrm{bim}\right)^{c, f, g}$ \\
\hline $\mathrm{Fe}-\mathrm{N}(1)$ & $1.959(3)$ & $2.090(7)$ & $2.121(3)$ & $2.172(3)$ \\
\hline $\mathrm{Fe}-\mathrm{N}(3)$ & $1.954(3)$ & $2.080(7)$ & $2.076(3)$ & $2.198(4)$ \\
\hline $\mathrm{Fe}-\mathrm{N}(5)$ & $1.958(3)$ & $2.079(7)$ & $2.151(4)$ & - \\
\hline $\mathrm{Fe}-\mathrm{N}(6)$ & $1.962(3)$ & $2.064(7)$ & $2.084(3)$ & -- \\
\hline $\mathrm{Fe}-\mathrm{N}(9)$ & $1.960(3)$ & $2.075(7)$ & $2.005(4)^{h}$ & -- \\
\hline $\mathrm{Fe}-\mathrm{N}(11)$ & 1.954(3) & $2.085(7)$ & $2.121(4)$ & $2.167(3)$ \\
\hline$\angle \mathrm{N}(1)-\mathrm{Fe}-\mathrm{N}(3)$ & $81.21(14)$ & $77.3(3)$ & $77.0(1)$ & $75.7(1)$ \\
\hline$\angle \mathrm{N}(5)-\mathrm{Fe}-\mathrm{N}(6)$ & $81.14(14)$ & $77.3(3)$ & $76.5(1)$ & -- \\
\hline$\angle \mathrm{N}(9)-\mathrm{Fe}-\mathrm{N}(11)$ & $81.43(14)$ & $77.2(3)$ & $78.4(2)$ & $76.4(2)^{g}$ \\
\hline$\angle \mathrm{N}(1)-\mathrm{Fe}-\mathrm{N}(9)$ & $176.98(15)$ & $165.3(3)$ & $167.4(2)$ & -- \\
\hline$\angle \mathrm{N}(3)-\mathrm{Fe}-\mathrm{N}(6)$ & $173.87(14)$ & 163.1(3) & $164.4(2)$ & $171.4(2)^{i}$ \\
\hline$\angle \mathrm{N}(5)-\mathrm{Fe}-\mathrm{N}(11)$ & $176.22(13)$ & 167.3(1) & $164.3(1)$ & $166.6(1)^{j}$ \\
\hline
\end{tabular}

${ }^{a}$ Numbering refers to $\mathbf{F e} \mathbf{I I I}_{\left(\mathbf{H}_{2} \text { bip }\right) \text { structure. }}$

${ }^{b}$ Data collected at $130 \mathrm{~K}$.

${ }^{c}$ Reference 27 .

${ }^{d}$ Data collected at $161 \mathrm{~K}$.

${ }^{e}$ Data collected at $298 \mathrm{~K}$.

$f$ Data collected at $300 \mathrm{~K}$.

${ }^{g} \mathbf{F e}^{\mathbf{I I}_{(\mathbf{H}}} \mathbf{H}_{\mathbf{b i m})}$ has a crystallographic mirror plane, N(11)-Fe-N(11A).

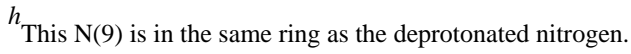

${ }^{i} \angle \mathrm{N}(3)-\mathrm{Fe}-\mathrm{N}(3 \mathrm{~A})$.

${ }^{j} \angle \mathrm{N}(1)-\mathrm{Fe}-\mathrm{N}(11)$. 


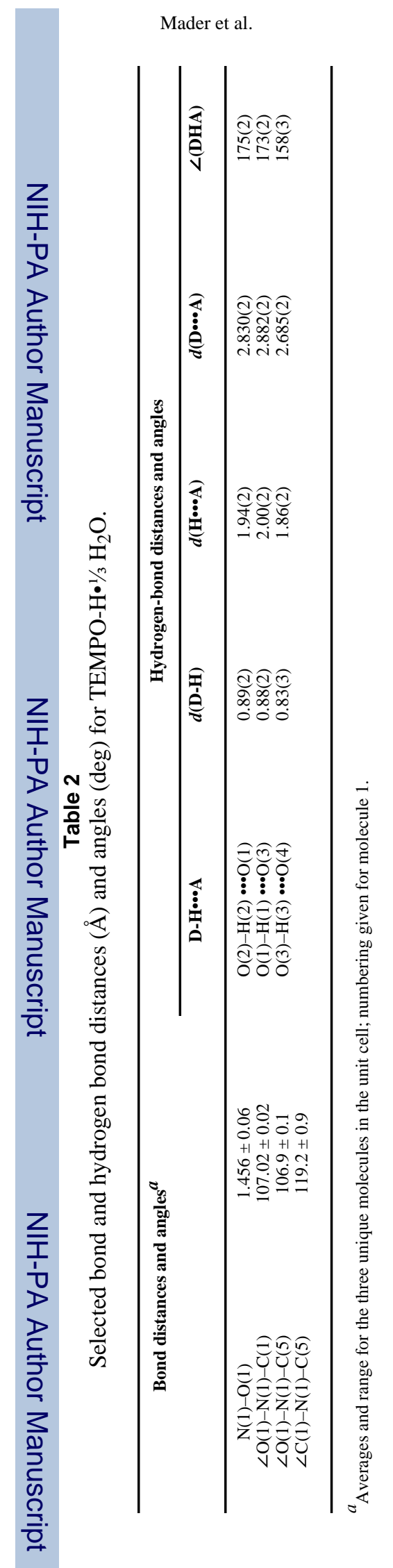

Page 31

$J$ Am Chem Soc. Author manuscript; available in PMC 2009 January 19. 


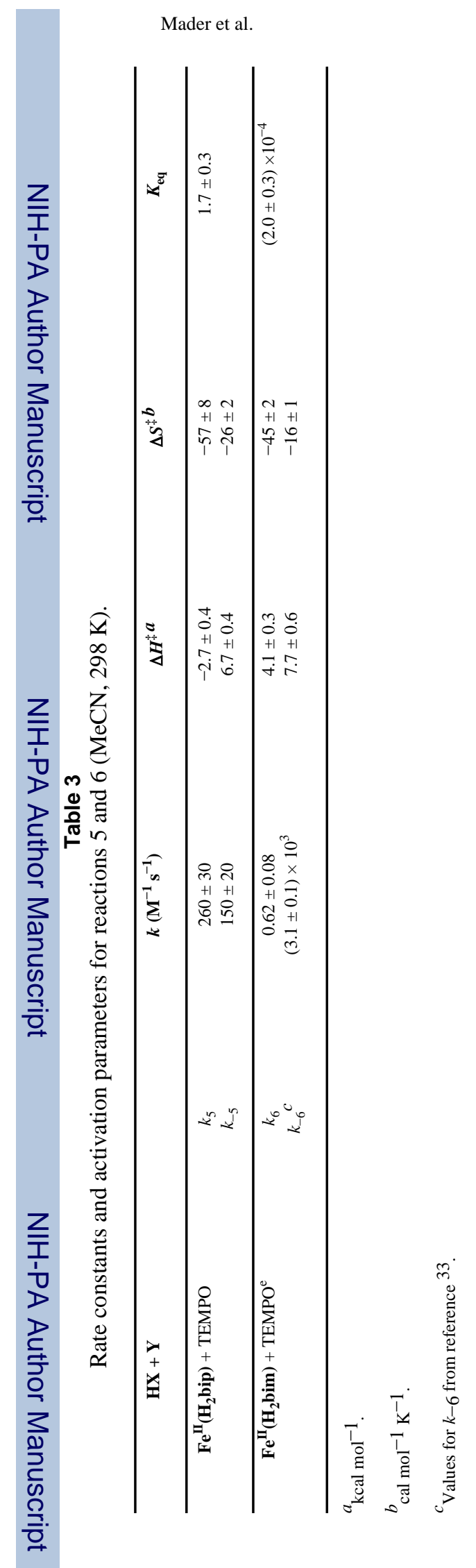

$J$ Am Chem Soc. Author manuscript; available in PMC 2009 January 19. 


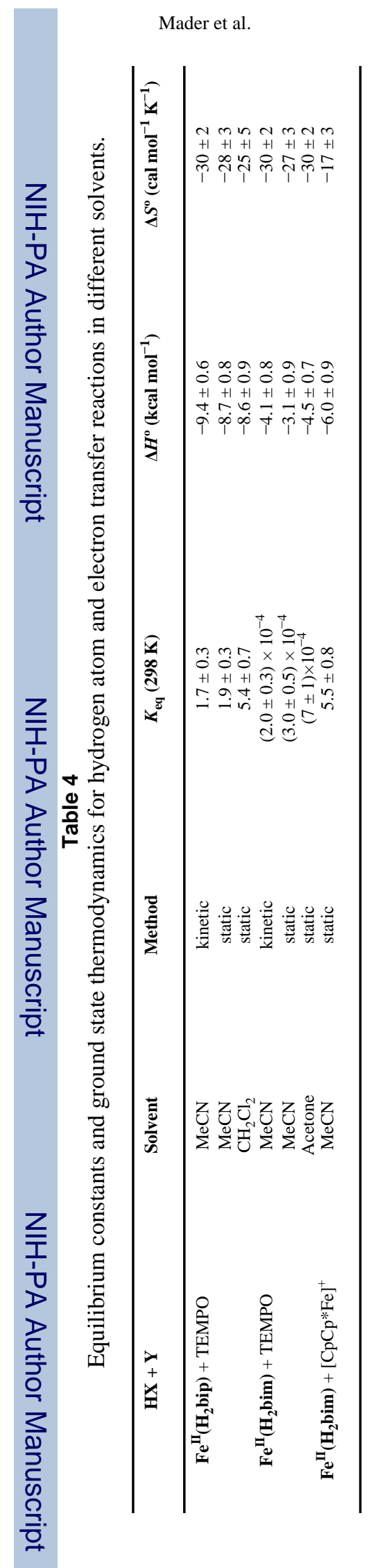

$J$ Am Chem Soc. Author manuscript; available in PMC 2009 January 19. 
Table 5

Gas phase entropy differences for HAT couples AH vs. $\mathrm{A}^{\bullet a}$

\begin{tabular}{|c|c|c|c|}
\hline $\mathbf{A H} / \mathbf{A}^{\bullet}$ & $S^{\mathbf{o}}(\mathbf{A H})_{\mathrm{g}}{ }^{a}$ & $S^{\mathbf{o}}\left(\mathbf{A}^{\bullet}\right)_{\mathrm{g}}^{a}$ & $\Delta S^{\circ}=S^{\circ}\left(\mathrm{A}^{\circ}\right)_{\mathrm{g}}-S^{\circ}(\mathrm{AH})_{\mathrm{g}}$ \\
\hline $\mathrm{HCl} / \mathrm{Cl}^{\bullet}$ & $44.67^{b}$ & $39.48^{b}$ & -5.19 \\
\hline $\mathrm{H}_{2} \mathrm{O} /{ }^{\circ} \mathrm{OH}$ & $45.13^{c}$ & $43.90^{d}$ & -1.23 \\
\hline $\mathrm{NH}_{3} / \mathrm{NH}_{2}$ & $46.07^{c}$ & $46.57^{d}$ & 0.50 \\
\hline $\mathrm{CH}_{4} / \mathrm{CH}_{3}$ & $44.54^{c}$ & $46.37^{d}$ & 1.83 \\
\hline $\mathrm{CH}_{3} \mathrm{OH} / \mathrm{CH}_{3} \mathrm{O}^{\circ}$ & $57.32^{c}$ & $55.99^{d}$ & -1.33 \\
\hline $\mathrm{C}_{6} \mathrm{H}_{5} \mathrm{OH} / \mathrm{C}_{6} \mathrm{H}_{5} \mathrm{O} \cdot$ & $75.34^{c}$ & $74.54^{c}$ & -0.80 \\
\hline $\mathrm{C}_{6} \mathrm{H}_{6} /{ }^{\circ} \mathrm{C}_{6} \mathrm{H}_{5}$ & $64.33^{c}$ & $68.37^{c}$ & 4.04 \\
\hline toluene/benzyl radical & $76.53^{c}$ & $76.06^{d}$ & -0.47 \\
\hline pyridine/3-pyridyl radical & $67.58^{c}$ & $69.84^{c}$ & 2.26 \\
\hline naphthalene/1-naphthyl radical & $79.89^{e}$ & $84.36^{e}$ & 4.47 \\
\hline
\end{tabular}

${ }^{a}$ Data in cal mol ${ }^{-1} \mathrm{~K}^{-1}$ at $298.15 \mathrm{~K}$ unless otherwise noted.

$b_{\text {Reference } 42 .}$

${ }^{c}$ Reference 43 .

$d_{\text {Reference } 44 .}$

${ }^{e}$ Reference 45 ; values at $300 \mathrm{~K}$. 